NBSIR 77.859

FILE COD?-

DO NOT RENI

\title{
THE THERMODYNAMIC PROPERTIES OF SLUSH HYDROGEN AND OXYGEA
}

H.M. Roder

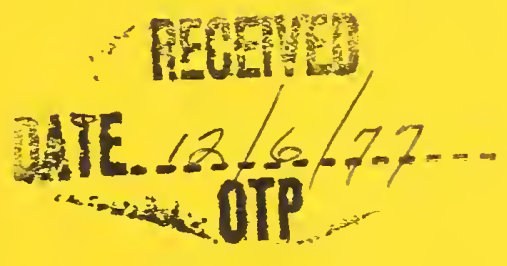

Cryogenics Division Institute for Basic Standards National Bureau of Standards Boulder, Colorado 80302

Final Report

Novemicer 1977

Fiectared for:

NASA-Jonnson Soace Center

Houszon, Texas 77058 

NBSIR 77.859

\section{THE THERMODYNAMIC PROPERTIES OF SLUSH HYDROGEN AND OXYGEN}

H.M. Roder

Cryogenics Division

Institute for Basic Standards

National Bureau of Standards

Boulder, Colorado 80302

Final Report

November 1977

Prepared for:

NASA-Johnson Space Center

Houston, Texas 77058

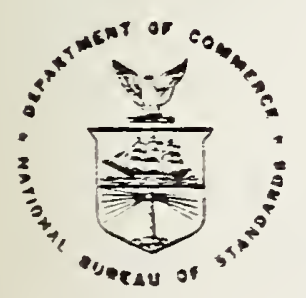

U.S. DEPARTMENT OF COMMERCE, Juanita M. Kreps, Secreiary

Sidney Harman. Under Secretary

Jordan J. Baruch, Assisiant Secretary for Science anc Tecnnology 
During the Gemini, Apollo, and Skylab programs, cryogenic systems were used as the source for fuel cell energy production. Throughout these programs the stored cryogens became one of the main limiting consumables involving vehicle lifetime. The critical nature of the cryogenic system required very accurate premission analyses. Not only were quantity calculations required but pressure range evaluation was also made to ensure that mission operations could be safely performed.

A potential major improvement in space shuttle operations involves the use of slush cryogens. Slush is the term used to describe a mixture of solid and liquid phases of a cryogen. The advantage of slush over liquid cryogens is a higher stored mass for the same occupied volume storage tank. Also, the latent heat of the solid in the slush increases storage time before venting occurs. This improved capacity and storage time make possible increased space flight time and distance.

The Cryogenics Division of the National Bureau of Standards provided the PVT data and the equations of state which were used during the Apolio and Skylab programs under the sponsorship of NASA. The basic data and computer programs are extended in the present report to provide the support necessary to an increased effort in slush research and mission analysis. This software technology is now available for all future space programs and is expected to have industrial application.

Paralleling the basic data effort NASA has been a prime driver in funding the development of slush cryogen technology. A slush hydrogen program conducted from 1965 to 1970 at NBS investigated several production methods, measured the pressure drop in flowing slush hydrogen, determined maxinum solid fraction and investigated several instruments to measure, solid fraction*. An experimental program currently underway at NBS is expected to demonstzate the safe and reliable production, storage and handing of slush hydrogen and oxygen in ground support equipment at NASA launch facilities.

* See page 21, 22 of Nat. 3ur. Stand. Technical Note 664, for references. 
1. INTRODUCTION . . . . . . . . . . . . . . . . . . . . . . . . . . . . . 1

2. BASIC THERMODYNAMIC CONSIDERATIONS . . . . . . . . . . . . . . 2

2.1 General . . . . . . . . . . . . . . . . . . 2

2.2 The Quality, Q . . . . . . . . . . . . . . . . . . . . 4

3. THE SOLID-LIQUID REGION FOR HYDROGEN . . . . . . . . . . . . . 5

3. I The Reference Values . . . . . . . . . . . . . . 5

3.2 The Melting Pressure Equation . . . . . . . . . . . 5

3.3 The Heats of Fusion at Elevated Pressures . . . . . . . . 6

3.4 Property Calculations . . . . . . . . . . . . . . . 6

3.5 Thermodynamic Consistency Checks . . . . . . . . . . . . 7

4. THE SOLID-VAPOR REGION FOR HYDROGEN . . . . . . . . . . . . . 7

4.1 The Reference Point . . . . . . . . . . . . . . . . 7

4.2 Vapor Pressure of the Solid . . . . . . . . . . . . . 8

4.3 Density of the Solid . . . . . . . . . . . . . . . 9 9

4.4 Heat Capacity of the Solid . . . . . . . . . . . . . . 9

4.5 Thermodynamic Consistency Checks . . . . . . . . . . . . 10

5. THE SOLID-IIQUID REGION FOR OXYGEN . . . . . . . . . . . . . . . II

5.1 The Reference Values . . . . . . . . . . . . . . . . . II

5.2 The Melting Pressure Equation . . . . . . . . . . . . 11

5.3 Property Estimation . . . . . . . . . . . . . . . 12

6. THE SOLID-VAPOR REGION FOR OXYGEN . . . . . . . . . . . . . . 12

6.1 The Reference Point . . . . . . . . . . . . . . . . . 13

6.2 Vapor Pressure of the Solid . . . . . . . . . . . . . 13

6.3 Density of the Solid . . . . . . . . . . . . . . . 13

6.4 Heat Capacity of the Solid . . . . . . . . . . . . . 14

6.5 Thermodynamic Consistency Checks . . . . . . . . . . . . 14

7. THE COMPUTER PROGRAMS FOR SLUSH HYDROGEN AND SLUSH OXYGEN . . I5

7.1 Input . . . . . . . . . . . . . . . . . . . . 15

7.2 Output . . . . . . . . . . . . . . . . . . 15

7.3 Flow Charts. . . . . . . . . . . . . . . . I6

7.4 Program Listings, Hydrogen . . . . . . . . . . . . . . 16

7.5 Program Listings, Oxygen . . . . . . . . . . . . . . 16

7.6 Test Programs, Sample Output . . . . . . . . . . . . 16

$7: 7$ Unit Conversions . . . . . . . . . . . . . . . 18

8. ERROR ESTIMATES, FURTHER WORK . . . . . . . . . . . . . . . 18

9. SUMMARY . . . . . . . . . . . . . . . . . . . . . . . . . . . . 22

10. REFERENCES . . . . . . . . . . . . . . . . . . . . . . . . . 23 
APPENDIX A. PROGRAM LISTINGS HYDROGEN . . . . . . . . . . . . . . . 26

APPENDIX B. PROGRAM LISTINGS OXYGEN • . . . . . . . • . . . . • . . 30

APPENDIX C. TEST PROGRAM HYDROGEN . . . . . . . . . . . . . . . . . 33

APPENDIX D. TEST PROGRAM OXYGEN . . • . . . . . . . . • . . . . . 35

APPENDIX E. CONVERSION FACTORS, HYDROGEN, . . . . . . . . . . . . . 37

APPENDIX F. CONVERSION FACTORS, OXYGEN . • . . • . • . . • . • . . 37

\section{SYMBOLS}

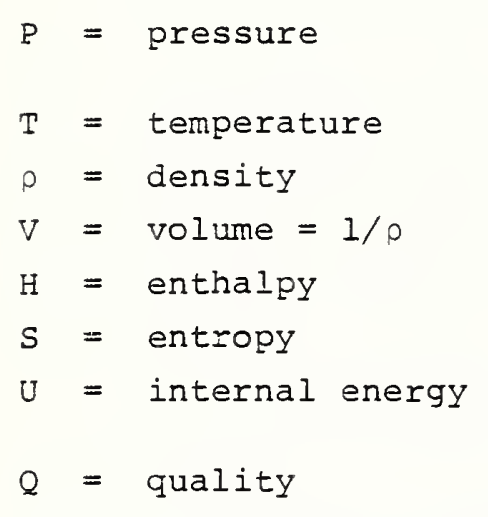

$\frac{\mathrm{dP}}{\mathrm{dT}}=$ derivative of vapor pressure or melting pressure

$\mathrm{T}^{\prime}=$ temperature shifted to a new scale

$c_{p}=$ specific heat at constant pressure

$\mathrm{C}_{\mathrm{v}}=$ specific heat at constant volume

$\Delta \mathrm{H} \quad=$ enthalpy difference

$\Delta S=$ entropy difference

$\mathrm{C}_{\text {SAT }}=$ specific heat of saturated solid or saturated liquid

$A, B, C, \alpha, C, P_{0}=$ coefficients in vapor pressure or melting pressure equations

\section{SUBSCRIPTS}

liquid $=$ liquid phase
vapor $=$ vapor phase
solid $=$ solid phase
$t$
melt $=$ triple point

fusion

sublimation

vaporization

\section{UNITS}

The primary variables in the computer programs are

Pressure in atmospheres

Density in moles/liter, and

Temperature in Kelvin.

Conversions to other SI units and units normally used in applied problems are given in Appendices $E$ and $F$. 
Hans M. Roder

Cryogenics Division

Institute for Basic Standards

National Bureau of Standards

Boulder, Colorado 80302

The thermodynamic properties of hydrogen and oxygen have been calculated for temperatures both below and above the triple point. values of the various physical properties required for the computations are either taken from the iiterature, or are extrapolated. If extrapolated, the extrapolations are based on the known behavior of other simple fluids. The results are presented in the form of computer programs which cover two regions of the phase diagram, solid-vapor, and solid-liquid. Input to the programs is temperature and quality. The properties returned include pressure, density, enthalpy, entropy and internal energy. The present programs for slush hydrogen and slush oxygen are an extension of and depend upon the equations of state developed previously for these gases.

Key words: Computer programs; enthalpy; entropy; hydrogen; internal energy; Iiquid; oxygen; PVT; quality; slush; solid; vapor.

\section{INTRODUCTION}

Slush is the term used to designate a mixture of solid and liquid phases of the gas under consideration. There are two major reasons for the current interest in slush. First, since solid is more dense than liquid, slush offers a way to carry a larger quantity of the cryogen in a container of fixed volume, as compared to the liquid alone. Second, since the solid melts, absorbing heat, slush offers a way to lengthen the time that the cryogen can be stored in a fixed volume container before venting has to occur.

We have included the solid-vapor region in this study because slush is currently produced by a freeze-thaw process. This means the properties of the vapor at temperatures just below the triple point are also of concern. Further, the properties of this two phase region are of interest in another application, subliming refrigerators, which are used to cool infrared detectors.

The properties of concern in this study are temperature, pressure, density, enthalpy, entropy and internal energy. Internal energy was added to the set because the principal applications at present involve containers of fixed volume. The regions of the phase diagram covered in this report, solid-vapor and solid-liquid, are both two phase regions. In analogy to the familiar quality used in liquid-vapor problems, we have incluaed quality as a parameter in this study. 
The thermodynamic properties described in this report are consistent with and should be viewed as an extension of the two equations of state developed previously, the equation of state for hydrogen by Roder and McCarty (1975), and the equation of state for oxygen by Weber (1977a, 1977b). The single phase regions of each gas for liquid, and fluid gas or vapor as well as the liquid-vapor two phase region are defined by these equations of state. The present slush routines call on the equations of state to define liquid properties along the melting line and vapor properties on the vapor boundary of the solid-vapor region.

\section{BASIC THERMODYNAMIC CONSIDERATIONS}

\subsection{General}

Consider a pressure temperature phase diagram shown schematically in figure 1. We recognize the melting line, the vapor pressure curve of the liquid and the vapor pressure of the solid. These curves define the boundaries of the various phases, solid, liquid, and vapor. They intersect at the triple point. It is from a plot such as this that the triple point takes its name. What this phase diagram does not show is the variation of density. One unique aspect of any two phase regime liquid-vapor solid-vapor or solid-liquid is that the pair $P, T$ on a phase boundary encompasses a large range of densities. We could consider a plot in the three variables pressure, density and temperature, however, consider instead the more Eamiliar $T-S$ diagram shown schematically in figure 2. This diagram is also a phase diagram. We recognize the single phase regions solid, liquid and vapor. We can also see the various two phase regions where two phases are in equilibrium. In a diagram of tisis kind the triple point gets stretched into a line. The density variation can also be included. For example, the density at point 1 in figure 2 corresponds to the density of the solid at the triple point, point 2 to the liquid triple point density, and point 3 to the vapor density at the triple point.

The regions already defined by the major equations of state are shown shaded. We will, in this report, cover the two phase regimes solid-liquid and solid-vapor. If we assume that the $\mathrm{P}-\mathrm{T}$ relation of the boundary is available, then to define a region we need only define the properties at the boundaries. For the true slush region, solid-liquid, we would have to know density, enthalpy, entropy and internal energy at both the liquid and solid boundaries. The liquid side is already defined for us by the intersection of the equation of state and the melting pressure curve. It remains to define the other boundary in this case the solid side. The actual approach depends on what pieces of experimental data are available to guide us, and these are discussed in detail in sections that follow. 


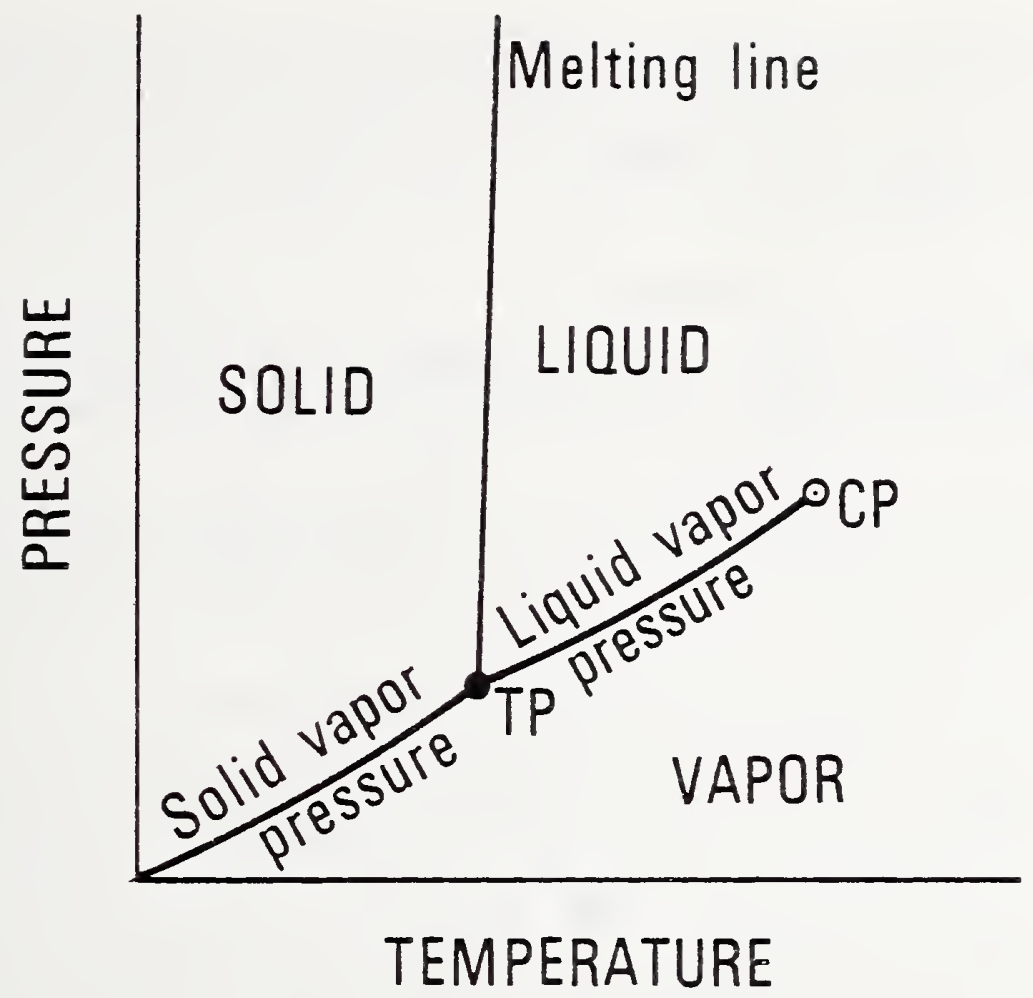

Figure 1. Pressure vs. Temperature, schematic.

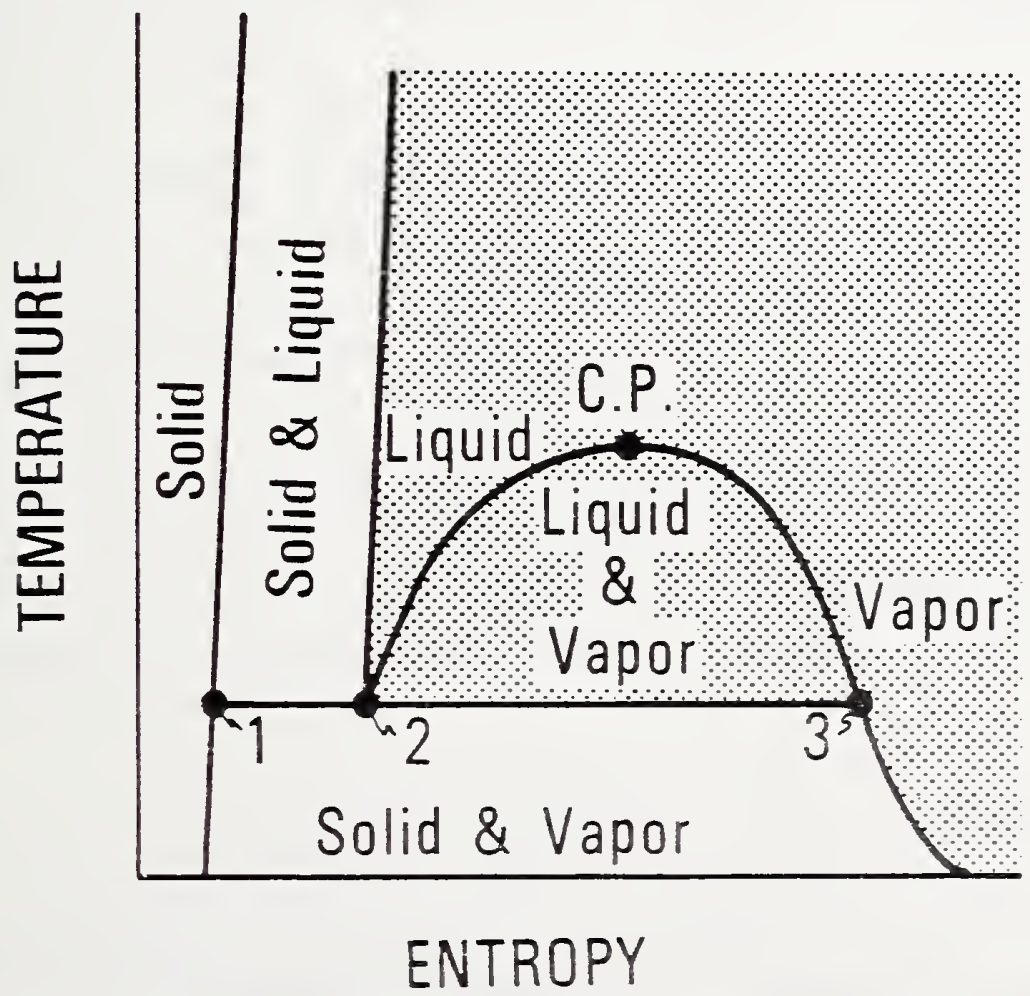

Eigure 2. Temperature vs. Entropy, schematic shaded area is covered by the 32 -term MBWR. 
A fundamental relation governs the various two phase regimes. This equation is called the Clausius-Clapeyron equation, and we will use it extensively. Written out for each of the three two phase regimes the equation reads as follows:

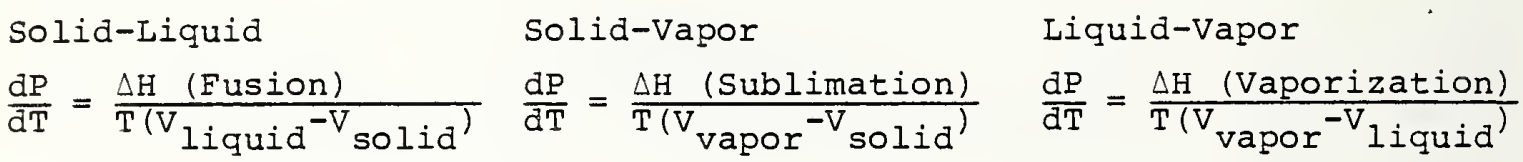

The equation relates a latent heat, the pressure-temperature derivative at the appropriate phase boundary and the volume change corresponding to the phase change in question. If the available data are redundant, then we are in a position to make thermodynamic consistency checks. Quite often the list of available data is minimal and the opportunity for consistency checks is lost. When elements of data are missing we are forced to calculate the unknown pieces of information from the clausius-clapeyron equation. For example, the volume change on fusion is usually not measured experimentally. The heat of fusion is normally measured only at the triple point, not at elevated temperatures or pressures. If we wish to know the volume change on fusion, say at the triple point, then we must calculate it from the experimentally measured heat of fusion and the derivative of the melting pressure equation.

\subsection{The Quality, Q}

The concept of quality is familiar to most engineers who have solved liquid-vapor problems. The conventional quality is defined as the percent (by mass) of the vapor phase present, or:

$$
\begin{aligned}
& Q=\left(\mathrm{V}-\mathrm{V}_{\text {liquid }}\right) /\left(\mathrm{V}_{\text {vapor }} \mathrm{V}_{\text {liquid }}\right) \text { for volume, and similarly } \\
& \mathrm{Q}=\left(\mathrm{H}-\mathrm{H}_{\text {liquid }}\right) /\left(\mathrm{H}_{\text {vapor }} \mathrm{H}_{\text {liquid }}\right) \\
& \mathrm{Q}=\left(\mathrm{S}-\mathrm{S}_{\text {liquid }}\right) /\left(\mathrm{S}_{\text {vapor }} \mathrm{S}_{1 \text { Iquid }}\right) \text { and } \\
& Q=\left(\mathrm{U}-\mathrm{U}_{\text {liquid }}\right) /\left(\mathrm{U}_{\text {vapor }} \mathrm{U}_{\text {liquid }}\right) .
\end{aligned}
$$

Since it is easy to make an error we caution that the expression in terms of density is:

$Q=\left[\frac{\rho_{1 \text { iquid }} \rho_{\text {vapor }}}{\rho}-\rho_{\text {vapor }}\right] /\left(\rho_{1 \text { iquid }}{ }^{-\rho_{\text {vapor }}}\right)$

From these equations it is apparent that $Q=0.0$ on the liquid side, i.e., the denser side, and that $Q=1.0$ on the vapor side, i.e., the less dense side. 
For the other two phase regimes solid-liquid and solid-vapor we will use a defined quality $Q$ defined in a manner quite analogous to that for liquid-vapor above. Q will be 0.0 on the dense side, i.e., the solid, and $Q$ will be 1.0 on the less dense side. The equations read as follows:

$$
\begin{aligned}
& \text { Solid-Liquid } \\
& Q=\left(V-V_{\text {solid }}\right) /\left(V_{\text {liquid }}-V_{\text {solid }}\right) \quad Q=\left(V-V_{\text {solid }}\right) /\left(V_{\text {vapor }}-V_{\text {solid }}\right) \\
& \mathrm{Q}=\left(\mathrm{H}_{\mathrm{H}} \mathrm{H}_{\text {solid }}\right) /\left(\mathrm{H}_{\text {liquid }} \mathrm{H}_{\text {solid }}\right) \mathrm{Q}=\left(\mathrm{H}_{\mathrm{H}} \mathrm{H}_{\text {solid }}\right) /\left(\mathrm{H}_{\text {vapor }} \mathrm{H}_{\text {solid }}\right) \\
& Q=\left(s_{\text {solid }}\right) /\left(s_{\text {liquid }}{ }^{-S_{\text {solid }}}\right) \quad Q=\left(S-s_{\text {solid }}\right) /\left(s_{\text {vapor }}{ }^{-S_{\text {solid }}}\right) \\
& Q=\left(U-U_{\text {solid }}\right) /\left(U_{\text {liquid }}-U_{\text {solid }}\right) \quad Q=\left(U-U_{\text {solid }}\right) /\left(U_{\text {vapor }}-U_{\text {solid }}\right)
\end{aligned}
$$

\section{THE SOLID-LIQUID REGION FOR HYDROGEN}

Prior work on the thermodynamic properties of this region include the experimental work and the calculations by Dwyer, et al. (1965a,b) and by cook, et al. (1965). In the present report the thermodynamic properties along the liquid boundary of this region are defined from the intersection of the 32-term modified Benedict-Webb-Rubin (MBWR) equation of state as presented by Roder and McCarty (1975) with the melting pressure equation (Goodwin, 1962). The elements of data available to describe the region are limited. In the sections that follow we describe the reference values chosen for the property calculations, the melting pressure equation of the solid, the heats of fusion at elevated pressures, the property calculations, and thermodynamic consistency checks.

\subsection{The Reference Values}

Since the available set of data is limited we are forced to calculate changes in properties for this region from the clausius-clapeyron equation. To obtain values for the solid boundaries these changes are applied from the liquid boundary. In effect, for a given temperature the values obtained from the 32-term equation of state and the melting line are used as starting point, or point of reference. At the triple point temperature the procedure leads to values for the solid that are used as reference point for the solid-vapor region (see section 4.1 ).

\subsection{The Melting Pressure Equation}

The equation used is the one developed by Goodwin (1962), except that we shift the temperature scale by $0.003 \mathrm{~K}$ to match the triple point temperature and pressure of the liquid vapor pressure curve used with the 32-term MBWR. The shift insures that the melting pressure equation and the liquid vapor pressure equation intersect at the triple point, $13.800 \mathrm{~K}$ and $0.0695 \mathrm{~atm}$, which are the values chosen for the basic 32-term equation of 
state. With the temperature shift Goodwin's equation becomes:

$\frac{P-P_{t}}{T^{\prime}-T_{t}}=A$ e $-\frac{\alpha}{T^{\prime}}+B T^{\prime}$

where $T^{\prime}=T+0.003$ in kelvin, $A=30.3312, \alpha=5.693, B=2 / 3, P_{t}=0.0695$ atm and $T_{t}=13.803$.

\subsection{The Heats of Fusion at Elevated Pressures}

These values were determined experimentally by Dwyer, et al. (1965b). The authors represent the experimental results by a straight line in pressure. We select the value of $117.277 \mathrm{~J} / \mathrm{mol}(28.03 \mathrm{cal} / \mathrm{mol}$, Woolley, et al., 1948) for the heat of fusion at the triple point, partially to remain consistent with the earlier thermodynamic calculations, and partially because this value is quite close to the average of all experimental determinations (see table 9-3, Roder, et al., 1973). Shifting the Dwyer, et al. equation to pass through the selected value the equation used for the heats of fusion becomes:

$\Delta \mathrm{H}_{\text {fusion }}=(28.02693164+0.044149 \mathrm{P}) \cdot 4.184$

where $\Delta \mathrm{H}_{\text {fusion }}$ is in $\mathrm{J} / \mathrm{mol}$ and $\mathrm{P}$ in atm. The uncertainty in $\Delta \mathrm{H}_{\text {fusion }}$ remains essentially as estimated by Dwyer, et al. (1965b), around 1\%.

\subsection{Property Calculations}

To find the values of the various properties on the solid boundary we calculate the volume and entropy changes from the clausius-clapeyron equation. The melting pressure equation and the heats of fusion were given in the previous sections. The relations are:

$P=P_{\text {melt }}(T)$

$\frac{d P}{d T}=\frac{d\left(P_{\text {melt }}\right)}{d T}$

$V_{\text {solid }}=V_{\text {Iiquid }}-\Delta V_{\text {fusion }}$ with $\Delta V_{\text {fusion }}=\frac{\Delta H \text { (fusion) }}{T \frac{d P}{d T}}$

$\mathrm{H}_{\text {solid }}=\mathrm{H}_{\text {liquid }}-\Delta \mathrm{H}_{\text {Eusion }}$

$S_{\text {solid }}=S_{\text {liquid }}-\Delta S_{\text {fusion }}$ with $\Delta S_{\text {Eusion }}=\Delta H_{\text {Eusion }} / T$. 
The internal energy for the solid follows from the thermodynamic relation $\mathrm{U}=\mathrm{Hi}-\mathrm{PV}$.

\subsection{Thermodynamic Consistency Checks}

Since the available set of data is limited, the checks that can be made are limited also. We can examine the change of volume on fusion as a function of temperature. We expect the volume change to decrease as the temperature increases, it does. The values obtained from the heats of fusion through the Clausius-Clapeyron equation are in excellent agreement with the experimental volume changes published by Bartholome (1936) for normal hydrogen as shown in table 1 .

Table 1. Volume Changes on Fusion at Elevated Temperatures

$\mathrm{T}$

$\begin{array}{ll}13.96 & 2.83 \\ 16.43 & 2.31 \\ 18.24 & 2.03\end{array}$

This Report

2.81

2.26

2.02
$\%$ .58 2.15 .61

Considering nitrogen and argon we would expect that the entropy change on fusion for hydrogen should decrease as the temperature increases. Quantitative comparisons cannot be made; however, this expectation is at least qualitatively fulfilled.

\section{THE SOLID-VAPOR REGION FOR HYDROGEN}

Prior work on the thermodynamic properties of this region include calculations by Mullins, et al. (1961), the T-S chart by Sindt and Mann (1966) and the survey by Roder, et al. (1973). The thermodynamic properties along the vapor boundary of this region are available from the intersection of the 32-term MBWR (Roder and McCarty, 1975) and the solid vapor pressure curve defining the boundary of the region. The elements required to complete the description of the region are the reference point for all properties, the vapor pressure equation of the solid, the density of the solid, and the heat capacity of the solid.

\subsection{The Reference Point}

We wish to integrate this region in a thermodynamically consistent way with the basic 32-term equation of state. The simplest thing we can do is to refer the properties of the solid at the triple point to those obtained from the 32-term MBWR for the liquid at the triple point. Specifically, we require that at the triple point temperature: 
vapor pressure of the solid = vapor pressure of the liquid

$$
\begin{aligned}
& \mathrm{V}_{\text {solid }}=\mathrm{V}_{\text {liquid }}-\Delta \mathrm{V}_{\text {fusion }} \\
& \mathrm{H}_{\text {solid }}=\mathrm{H}_{\text {liquid }}-\Delta \mathrm{H}_{\text {fusion }} \\
& \mathrm{S}_{\text {solid }}=\mathrm{S}_{\text {liquid }}-\Delta \mathrm{S}_{\text {fusion }}
\end{aligned}
$$

Internal energy of the solid follows through the thermodynamic relation $\mathrm{U}=\mathrm{H}-\mathrm{PV}$. $\Delta \mathrm{H}$ fusion' the heat of fusion selected for the triple point is

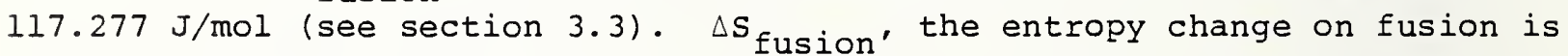
defined thermodynamically as $\Delta \mathrm{H}_{\text {fusion }} / \mathrm{T} . \quad \Delta \mathrm{V}_{\text {fusion' }}$ the volume change on fusion is calculated from the Clausius-Clapeyron equation and the melting pressure derivative (see section 3.4). The result for the triple point with $T_{t}=13.800 \mathrm{~K}$ is $\Delta V_{\text {fusion }} \simeq 2.86_{4} \mathrm{~cm}^{3} / \mathrm{mol}$.

Having established a reference point or benchmark we can look next at the description of the remainder of the region.

\subsection{Vapor Pressure of the Solid}

One of the drawbacks of the earlier calculation by Mullins, et al. (1961) is that the authors presented no explicit equation for the vapor pressure of the solid, indeed they could not because one can either force exact thermodynamic consistency or use an explicit vapor pressure equation, but not both. Experimental measurements of the vapor pressure of solid hydrogen exist to quite low temperatures (Woolley, et al., 1948; Borovik, et al., 1960; and Harrison, et al., 1962). However, we will use these values only as a check on the extrapolation of the vapor pressure curve to low temperatures.

The form of the vapor pressure equation is dictated by thermodynamics. Integration of the Clausius-Clapeyron equation assuming the vapor phase to be an ideal gas leads to the Kirchhoff-Rankine equation:

$\log P=A / T+B \log T+C$

We use this equation but subject it to the following constraints:

1. $P_{t}=0.0695 \mathrm{~atm}, \mathrm{~T}_{t}-13.800 \mathrm{~K}$. To insure that this equation intersects the melting equation and the liquid vapor pressure equation at the triple point which is defined by the liquid vapor pressure equation used with the 32-term MBWR.

2. $\frac{\mathrm{dP}}{\mathrm{dT}}$ at the triple point temperature $=0.04566744 \mathrm{~atm} / \mathrm{K}$. This constraint defines the derivative dP/dT of the solid vapor pressure curve at the triple point temperature, and through the Clausius-Clapeyron equation the heat of sublimation. The value of the derivative is chosen so that: 
where $\triangle H_{\text {fusion }}$ is the value chosen in sections 3.3 and 4.1 , and the $\triangle H_{\text {vaporization }}$ is determined by the 32 -term MBWR and its companion liquid vapor pressure equation.

3. That the vapor pressure at $10 \mathrm{~K}$ be $0.00255940 \mathrm{~atm}$. The last requirement is the best compromise to insure thermodynamic consistency of the heat of sublimation down to $10 \mathrm{k}$. The point is discussed in more detail in the section on thermodynamic consistency below.

With 3 degrees of freedom and three constraints the coefficients of the solid vapor pressure equation are uniquely determined. They are:
$A=-90.77568949$
$B=2.489830940$
and $\mathrm{C}=$
4.009857354

where $P$ is in $\mathrm{mm} \mathrm{kg}$ and $\mathrm{T}$ is in $\mathrm{K}$.

Intercomparison to the available experimental vapor pressures shows the maximum deviation in pressure down to $10 \mathrm{~K}$ is less than $1 \%$. The simple equation cannot, however, represent the data down to low temperatures, say 3 or $4 \mathrm{k}$. In this temperature range the departure between predicted and experimental vapor pressures increases to nearly $200 \%$. Additional terms in the vapor pressure equation improve the representation of the vapor pressures but not the heats of sublimation calculated from the vapor pressure derivative.

\subsection{Density of the Solid}

From the survey by Roder, et al. (1973) we select the solid volumes published by Ahlers (1963) primarily because we expect these values to be in accord with the heat capacity measurements selected in tine next section. More recent publications (Ancerson and Swenson, 1974) prefer values which differ by as much as $1.5 \%$ from the ones selected especially at the lower temperatures. Ahlers' results can be represented by a parabolic function from 6 to $13.8 \mathrm{~K}$. We sifit this function to pass through the designated value of the solid density at the triple point. The resulting relation is:

$\frac{1}{P_{\text {solid }}}=v_{\text {solid }}=22.77963478-0.031 T+0.005 T^{2}$

with $v_{\text {solid }}$ in $\mathrm{cm}^{3} / \mathrm{mol}$ and $T$ in $\mathrm{K}$. We estimate that the values of the solid srould be in error by no more than $0.4 \%$ at the triple point, and that the exror could increase to as much as $1.5 \%$ at $4 \mathrm{~K}$ or lower.

\subsection{Heat Capacity of the solid}

we recuire heat capacity values for the solid at saturation. The values selected were derived by Ahlers (1963) from his measurements of $C_{V}$ in the single phase solid. We prefer these values to earlier measurements because 
a closed loop third law check of entropy using these values is much more consistent than checks using the earlier measurements (See Roder, et al., 1965). Since several conventional representations do not seem to apply to the values for hydrogen, we settled on a simple interpolating polynomial which returns Ahlers' values to within $0.3 \%$ from $14 \mathrm{~K}$ down to $5 \mathrm{~K}$. Maximum deviations down to $3 \mathrm{~K}$ are $1.65 \%$, but the polynomial should not be used below $3 \mathrm{k}$. The power series used to represent $\mathrm{C}_{\mathrm{SAT}}$ is:

$C_{S A T}=-10 I .+87.75 \mathrm{~T}-26.95833333 \mathrm{~T}^{2}+4.25 \mathrm{~T}^{3}-0.041666667 \mathrm{~T}^{4}$

with $C_{\text {SAT }}$ in milli Joules/mole and $T$ in $K$.

We use the heat capacity in the thermodynamic relations:

$\Delta H=\int_{T}^{T} C_{S A T} d T$ and $\Delta S=\int_{T}^{T} \frac{C_{S A T}}{T} d T$

to calculate the changes in enthalpy and entropy from the reference values for the solid at the triple point.

\subsection{Thermodynamic Consistency Checks}

Once the vapor pressure of the solid is defined, we can perform a consistency check in the following way. We calculate the heat of sublimation first by taking the difference between vapor and solid enthalpies at the boundary, and second by calculating it from the clausius-clapeyron equation using solid and vapor volumes and the derivative of the solid vapor pressure curve. The enthalpy of the vapor is obtained from the 32-term equation of state, we note that these enthalpies depend on the specific heat of the ideal gas which is not defined below $10 \mathrm{~K}$ in the equation of state programs. The enthalpy of the solid is obtained from the integration of the heat capacity of the solid. The difference of these two values, the heat of sublimation, calculated in this way is not particularly sensitive to the value of pressure chosen. In the other calculation, however, the heat of sublimation depends on the vapor volume obtained from the equation of state and on the derivative of the solid vapor pressure curve and is quite sensitive to changes in pressure. We select the value of the pressure at $10 \mathrm{~K}$, the third constraint, to minimize the departures between the heats of sublimation calculated by the two different methods between 13.8 and $10 \mathrm{~K}$. The intercomparison of the heats of sublimation is shown in table 2 ; the departures do not exceed $0.1 \%$. 
Table 2. Intercomparison of the Heats of Sublimation of Hydrogen

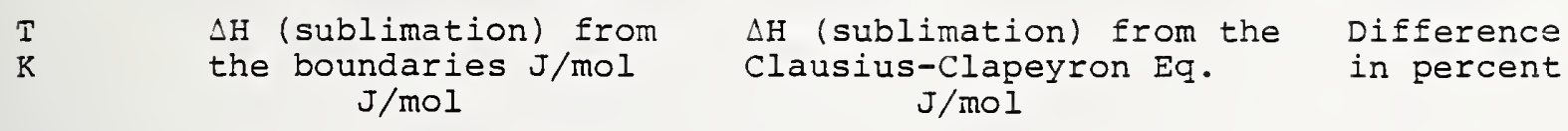

$\begin{array}{rrrr}10 & 961.234 & 960.300 & 0.10 \\ 11 & 979.262 & 979.169 & 0.01 \\ 12 & 996.088 & 996.584 & -0.04 \\ 13 & 1011.351 & 1011.900 & -0.05\end{array}$

$13.8 \quad 1022.137$

1022.137

defined to be the same

\section{THE SOLID-LIQUID REGION FOR OXYGEN}

With the exception of the melting curve and the heat of fusion at the triple point prior work on the properties of this region is non-existent. We are therefore forced to estimate all of the thermodynamic properties from the Clausius-Clapeyron equation using other simple gases as model fluids. The thermodynamic properties along the liquid boundary of this region are defined from the intersection of the 32-term MBWR equation of state and the melting pressure equation presented by Weber (1977b). Weber's version of the 32-term MBWR rather than an earlier version (Stewart, et al., 1972) is used because it includes new values of PVT (Weber, 1977a) which go to high pressures ( 200 bar). An additional advantage of Weber.'s formulation is that the vapor pressure curve and the melting line intersect at the defined triple point. In the sections that follow we describe the reference values chosen for the property calculations, the melting pressure equation of the solid, and the property estimation.

\subsection{The Reference Values}

Since the available set of data is limited, we are forced to calculate changes in properties for this region from the clausius-clapeyron equation. To obtain values for the solid boundaries these changes are applied from the Iiquid boundary. In effect, for a given temperature the values obtained from the 32-term equation of state and the melting line are used as a starting point, or point of reference. At the triple point temperature the procedure leads to values for the solid that are used as a reference point for the solid-vapor region (see section 6.1). The enthalpy departure at the triple point has been estimated by weber (1977b) to be about $3 \mathrm{~J} / \mathrm{mol}$.

\subsection{The Melting Pressure Equation}

The equation used is the one developed by weber (1970) as modified by him (Weber, 1977a,b) to pass through the defined triple point. The equation reads 
$P=P_{t}+P_{0}\left[\left(T / T_{t}\right)^{C}-1\right]$

with $\mathrm{T}_{t}=54.359 \mathrm{~K}, \mathrm{P}_{t}=0.0014451 \mathrm{~atm}, \mathrm{P}_{\mathrm{o}}=2637.33 \mathrm{~atm}$, and $\mathrm{c}=1.769$. 5.3 Property Estimation

To estimate values of the various properties on the solid boundary of this region we will use the Clausius-Clapeyron equation. To do this we must make an educated guess as to how the heat of fusion, or the volume change on fusion, or the entropy change on fusion depends on pressure (or temperature). Considering the known behavior of hydrogen, argon, and nitrogen we postulate that oxygen should obey the following qualitative criteria:

1. The heat of fusion should increase as either pressure or temperature is increased,

2. The entropy of fusion should decrease as either pressure or temperature is increased, and

3. The volume change on fusion should decrease as either pressure or temperature is increased.

Direct scaling of the volume change for oxygen from hydrogen, argon, or nitrogen (see page 53, Sindt, Ludtke and Roder, 1970) is not successful; one of the criteria remains unfulfilled. Adopting a sort of an average between the two extreme assumptions

1. $\Delta H_{\text {fusion }}(T$ or $P)=$ constant, and

2. $\Delta \mathrm{S}_{\text {fusion }}(\mathrm{T}$ or $\mathrm{P})=$ constant

allows us to fulfill all three criteria over a range of experimentally plausible pressures, say up to 5000 psia. As for hydrogen we express the heat of fusion of oxygen as a linear function of pressure

$\Delta \mathrm{H}_{\text {fusion }}=(106.3+0.01126 \mathrm{P}) \cdot 4.184$

where $\Delta \mathrm{H}_{\text {fusion }}$ in in $\mathrm{J} / \mathrm{mol}$ and $\mathrm{P}$ is in atm. The value $106.3 \mathrm{cal} / \mathrm{mol}$ is taken at the triple point from the paper by Giauque and Johnston (1929). The uncertainty in the estimated heat of fusion should be no larger than the variation estimated for it, i.e., a maximum of $6 \%$ at the highest pressures.

With an estimate for the heat of fusion in hand the property calculations follow the relations given in section 3.4. Obviously, consistency checks cannot be made for this region.

\section{THE SOLID-VAPOR REGION FOR OXYGEN}

Prior work on the thermodynamic properties of this region includes the calculations by Mullins, et al. (1962). The thermodynamic properties along 
the vapor boundary of this region are available from the intersection of the 32-term MBWR (Weber, 1977b) and the solid vapor pressure curve defining the boundary of the region. The elements required to complete the description of the region are the reference point for all properties, the vapor pressure equation of the solid, the density of the solid, and the heat capacity of the solid.

\subsection{The Reference Point}

The reference point for this region is defined in exactly the same way as for hydrogen (see section 4.1). The heat of fusion at the triple point was experimentally measured by Giauque and Johnston (1929) to be $106.3 \mathrm{cal} / \mathrm{mol}$ $(444.8 \mathrm{~J} / \mathrm{mol})$. The triple point temperature, $54.359 \mathrm{~K}$, and the melting pressure equation are taken from Weber (1977b). The volume change on fusion at the triple point becomes approximately $0.940_{8} \mathrm{~cm}^{3} / \mathrm{mol}$.

\subsection{Vapor Pressure of the Solid}

The same general remarks apply to oxygen as they did to hydrogen. The vapor pressure equation is of the Kirchhoff-Rankine type

$\log P=\frac{-1096.562435}{T}-2.025578307 \log T+28.35976524$

with $T$ in kelvin and $F$ in $\mathrm{mm} \mathrm{Hg}$. The constraints used are:

1. $\mathrm{P}_{\mathrm{t}}=0.0014451 \mathrm{~atm}, \mathrm{~T}_{\mathrm{t}}=54.359 \mathrm{~K}$,

2. $\left|\frac{\mathrm{dP}}{\mathrm{dT}}\right|_{t}=0.000482427 \mathrm{~atm} / \mathrm{K}$, and

3. $P=0.000019200$ atm at $44 \mathrm{~K}$.

Intercomparisons with the available experimental vapor pressures of Aoyama and Kanda (1936) down to the $\beta-\gamma$ solid transition show departures of up to $30 \%$ in pressure.

\subsection{Density of the Solid}

Oxygen is an interesting solid because it occurs in three different solid structures. We are interested here only in the so-called y-solid which exists between the temperatures of $43.801 \mathrm{~K}$ (Kemp and Pickup, 1972) and the triple point, $54.359 \mathrm{~K}$. For this range of temperatures the thermal expansion measurements of Manzhelii, et al. (1966) the absolute measurement of Tolkachev and Manzhelii (1965) and the x-ray measurements of Barrett, et al. (1967) are in reasonable agreement, i.e., within $0.6 \%$. We represent the experimental results with a parabolic function forced to pass through the designated value at the triple point. The relation is 
$\frac{1}{\rho_{\text {solid }}}=V_{\text {solid }}=23.2808187-0.06772142868 \mathrm{~T}+0.001339285715 \mathrm{~T}^{2}$

with $\mathrm{V}_{\text {solid }}$ in $\mathrm{cm}^{3} / \mathrm{mol}$ and $\mathrm{T}$ in $\mathrm{K}$. The solid densities should be in error by no more than $0.6 \%$ in the range of temperatures covered.

\subsection{Heat Capacity of the Solid}

The experimental measurements on the $\gamma$-solid by Giauque and Johnston (1929) were represented by Mullins, et al. (1962) with a simple polynomial which is retained here

$C_{\text {SAT }}=16.908081-0.24181777 \mathrm{~T}+0.0024809089 \mathrm{~T}^{2}$

with $\mathrm{C}_{\text {SAT }}$ in cal/mol $(4.184 \mathrm{~J} / \mathrm{cal})$ and $\mathrm{T}$ in kelvin. Departures of the polynomial from the measured points are no larger than the stated error in the measurements, i.e., about $0.5 \%$ in $\mathrm{C}_{\mathrm{SAT}}$.

\subsection{Thermodynamic Consistency Checks}

These checks are performed as described in section 4.5 for hydrogen, except that here the temperature limitation is that of the $\beta-\gamma$ transition, i.e., 43.801 K. Results are shown in table 3. Departures between the different ways of calculating the heat of sublimation do not exceed $0.06 \%$.

Table 3. Intercomparison of the lieats of Sublimation of Oxygen

$\begin{array}{lccc}\mathrm{T}, \mathrm{K} & \begin{array}{c}\Delta \mathrm{H}_{\text {sublimation }} \\ \text { from the boundaries } \\ \mathrm{J} / \mathrm{mol}\end{array} & \begin{array}{c}\Delta \mathrm{H}_{\text {sublimation }} \\ \text { from the C-C Eq. } \\ \mathrm{J} / \mathrm{mol}\end{array} & \begin{array}{c}\text { Difference } \\ \mathrm{J} / \mathrm{mol}\end{array} \\ 44.000 & 8376.665 & 8376.109 & .556 \\ 45.000 & 8359.501 & 8359.234 & .267 \\ 46.000 & 8342.413 & 8342.344 & .069 \\ 47.000 & 8325.380 & 8325.433 & -.054 \\ 48.000 & 8308.379 & 8308.497 & -.118 \\ 49.000 & 8291.388 & 8291.527 & -.139 \\ 50.000 & 8274.383 & 8274.512 & -.129 \\ 51.000 & 8257.341 & 8257.443 & -.102 \\ 52.000 & 8240.238 & 8240.305 & -.067 \\ 53.000 & 8223.050 & 8223.083 & -.033 \\ 54.000 & 8205.751 & 8205.758 & -.007 \\ 54.359 & 8199.509 & 8199.509 & \text { defined to be the }\end{array}$




\section{THE COMPUTER PROGRAMS FOR SLUSH HYDROGEN AND SLUSH OXYGEN}

The phase boundaries and representations of the different properties along the phase boundaries described in the previous sections have been combined into two computer programs. The programs are in the form of subroutines:

SLH2 (TT, QQ, TP, PSI, DSL, HSL, SSI, USL)
SLO2 (TT, QQ, TP, PSL, DSL, HSL, SSL, USL)

where the variables in the parameter list are temperature, quality, triple point key, pressure, density, enthalpy, entropy, and internal energy.

\subsection{Input}

The user must specify temperature and quality. He may specify the triple point key depending on the temperature.

Temperature. The input temperature in kelvin should be between 10 and $22.60 \mathrm{~K}$ for hydrogen and between 44 and $58.2 \mathrm{~K}$ for oxygen. The programs will return answers for temperatures less than the lower limit, but the values returned become less and less reliable the lower the temperature. For temperatures greater than the upper limit an error message is printed: "T is too high, P will exceed 5000 psia."

Quality. A value for quality must be entered such that $0.0 \leq Q \leq 1.0$. A quality of 0.0 will cause the subroutine to return values on the denser side, i.e., the values of the solid. A quality of 1.0 causes the subroutine to return values on the less dense side, i.e., values of the vapor for the solid-vapor region (temperatures below the triple point), and values of the liquid for the solid-liquid region (temperatures above the triple point). If the input $Q$ is fractional the subroutine calculates the values of the properties on both boundaries of the region and then performs the ratio according to the equations given in section 2.2 .

Triple point key. For the special case when the input temperature is exactly equal to the triple point temperature, $13.800 \mathrm{~K}$ for hydrogen and $54.359 \mathrm{~K}$ for oxygen, the user must specify through the triple point key, TP, in which region he wants the subroutine to calculate the properties. $\mathrm{TP}=0.0$ means that the program will return properties from the solid-liquid region, while $T P=1.0$ insures that the program calculates the triple point properties in the solid-vapor region.

\section{2 output}

The output from the program is handled through the parameter list. For a given input of $T$ and $Q$ (TP if appropriate) the output is unique, i.e., single-valued. The values returned are the slush pressure PSI in atm, the 
slush density DSL in mol/L, the slush enthalpy HSL in $\mathrm{J} / \mathrm{mol}$, the slush entropy SSI in $\mathrm{J} / \mathrm{mol}-\mathrm{K}$, and the slush internal energy USI in $\mathrm{J} / \mathrm{mol}$.

\subsection{Flow Charts}

The slush routines are detailed in the flow chart of figure 3 . The various phase boundaries and the interiors of the solid-liquid and solid-vapor regions are keyed according to the inset, which is just a repeat of the phase diagram already shown in figure 2 .

\subsection{Program Listings, Hydrogen}

A listing of the hydrogen program is given in Appendix A. The slush hydrogen routine calls on the program deck of the parent 32-term MBWR (Roder and McCarty, 1975). Those routines of the parent deck that had to be modified to insure consistency around the triple point are also listed in Appendix A. They are:

FUNCTION PRESSM(TT), and

SUBROUTINE RHOI (PP, DD,TT).

New routines developed for the slush application and listed in Appendix $A$ are:

FUNCTION DPDTMP (TT), and

FUNCTION FINDM $(P, T, D)$.

The first is simply the temperature derivative of the melting pressure curve, while the latter is an additional density finder. The FINDM routine differs from the normal FINDD density finder in that it requires a reasonable trial density in its calling parameters.

\subsection{Program Listings, Oxygen}

A listing of the oxygen program is given in Appendix B. The slush oxygen routine calls on the program deck of the parent 32-term MBWR (Weber, 1977b). Routines not available with the parent deck, or those that had to be modified are listed in Appendix B as well. They are:

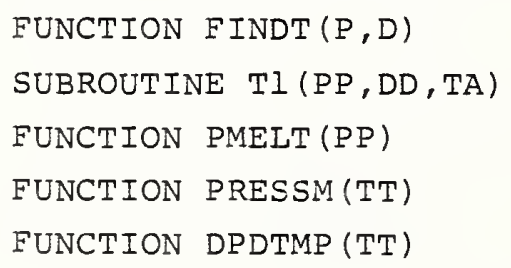

7.6 Test Programs, Sample Output

A sample program for hydrogen is shown in Appendix $C$; in Appendix $D$ for oxygen. The output from the test program for hydrogen in the form of an abbreviated table of values with particular attention to the triple point is given in table 4; the companion output for oxygen in table 5 . 
Subroutine SLH $_{2}$ (TT,QQ,TP,PSL,DSL, HSL,SSL,USL)

Subroutine $\mathrm{SLO}_{2}$ (T,,QQ,TP,PSL.DSL,HSL,SSL,USL)

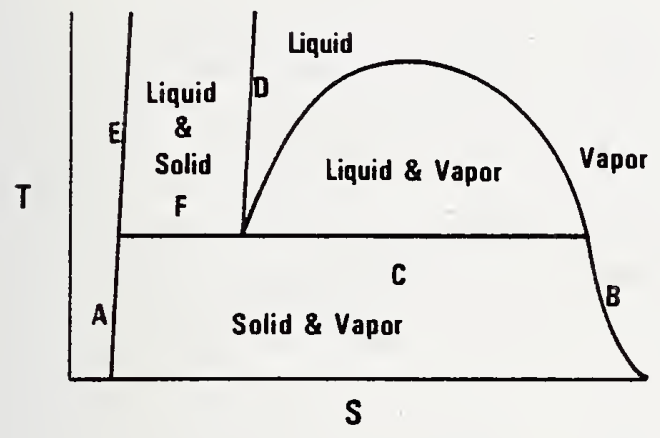

nter with temperature $\Pi$ and quality 00

$\mathbf{Q Q}=\mathbf{0}$ Properties on the denser side

$\mathbf{Q Q}=1$ Properties on the less dense side

QQ Fractional $\longrightarrow$ mixture properties

A - Solid below TP D - Liquid above TP

B - Vapor below TP E - Solid above TP

C - Mixture below TP F - Mixture above TP

Special Case, Temp. $\Pi \equiv$ Triple Point

TP=0. for Solid-Liquid Properties

$T P=1$. for Solid-Vapor Properties

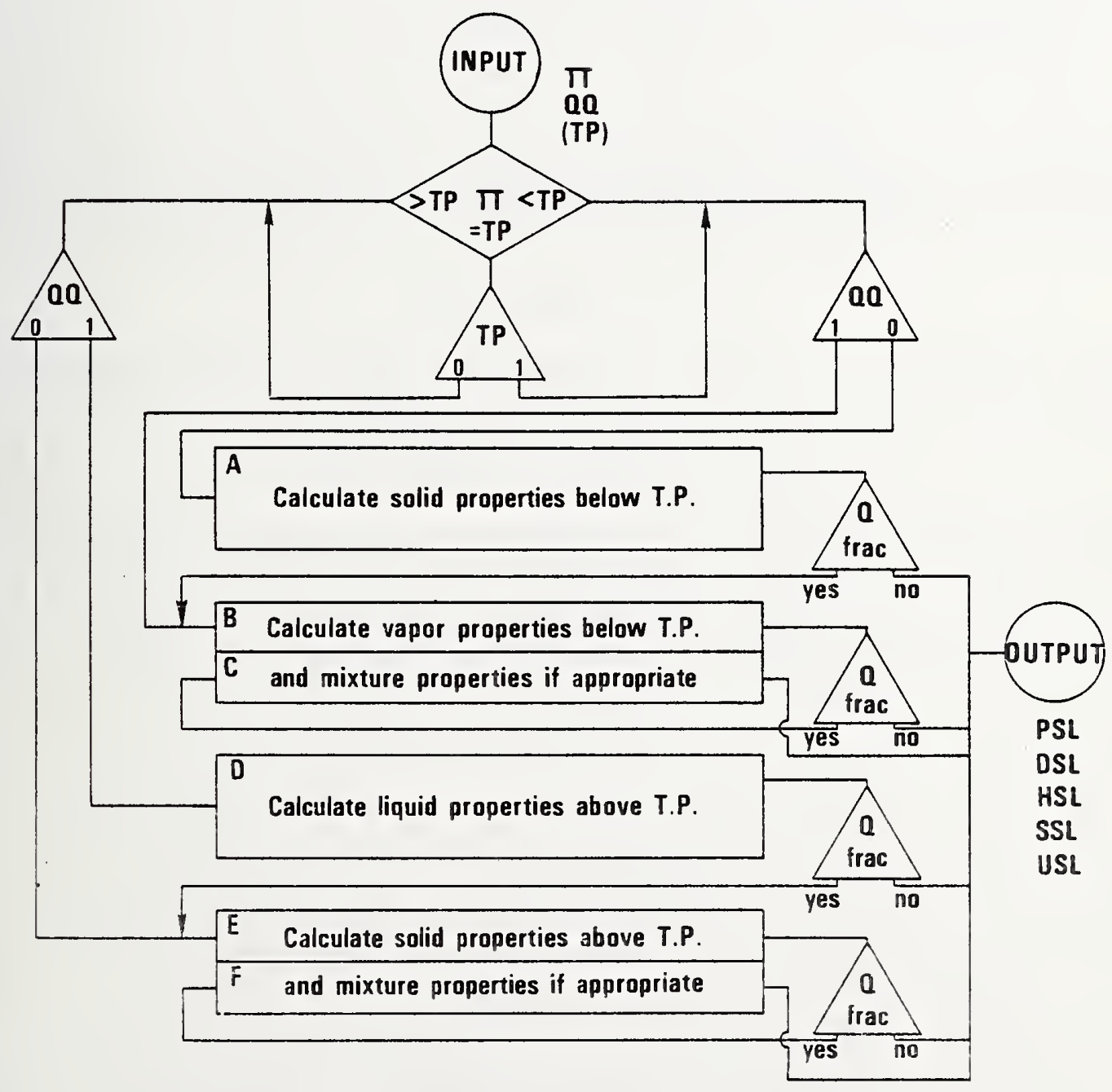

Figure 3. Flow chart of the subroutines $\mathrm{SLH}_{2}, \mathrm{SLO}_{2}$. 
The sample programs are intended to serve as test decks for running at other installations. They include a call to every possible combination of $T$ and $Q$ in the regions solid-liquid and solid-vapor. To round out the list of examples the liquid-vapor region, which is obtained from the parent 32-term MBWR, has also been illustrated.

The astute observer will note that the various properties in 1 ines 4 and 7 of tables 4 and 5 and also lines 6 and 14 and lines 9 and 13 should be pairwise identical, except of course for $Q$ and $T P$. To the extent that these lines are not identical thermodynamic inconsistencies remain. One of the inconsistencies arises from the fact that we carry 10 digits in the coefficients of the vapor pressure equations and the melting line. The pressures returned from each of the different functions at the triple point temperature are very nearly the same, however, they are not identical in every bit of the computer word. Entering the 32-term equation of state with slightly different values of the pressure results in slightly different values of vapor densities returned. The disagreement in entropy between lines 6 and 14 arises from an inconsistency inherent in the equation of state. This is shown simply by the fact that the $\Delta \mathrm{H}$ between lines 13 and 14 of tables 4 and 5 divided by the triple point temperature is not equal to the $\Delta S$ between lines 13 and 14. Several other discrepancies are attributable to rounding errors.

\subsection{Unit Conversions}

Common conversion factors for use with hydrogen are given in Appendix $\mathrm{E}$, while those for use with oxygen are shown in Appendix F.

\section{ERROR ESTIMATES, FURTHER WORK}

Whenever possible estimates of uncertainty were given in the sections that described the fitting or representation of a particular piece of experimental data. We summarize these uncertainties as maximum errors in the different properties used in the computer programs in table 6 . 


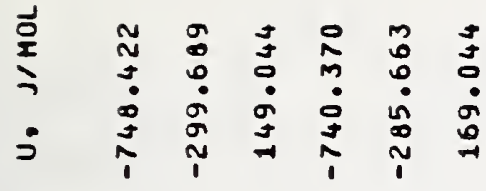

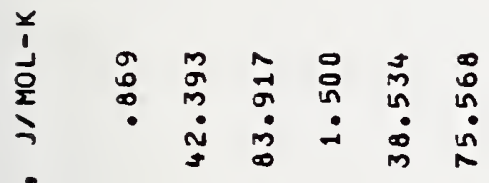

in

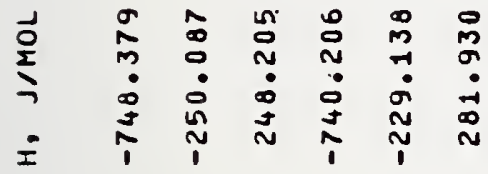

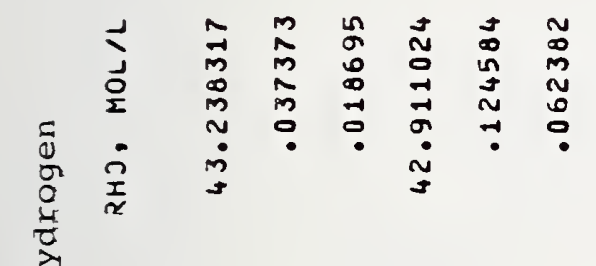

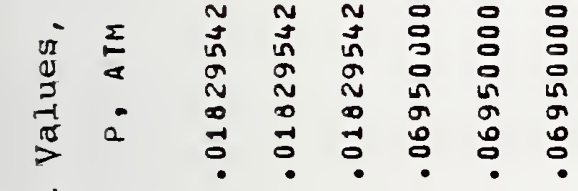

$\underset{U 1}{\text { Un }}$

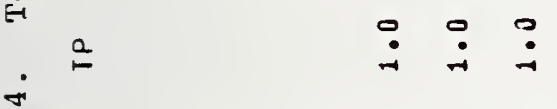

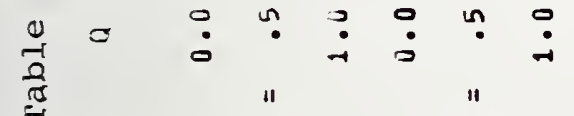

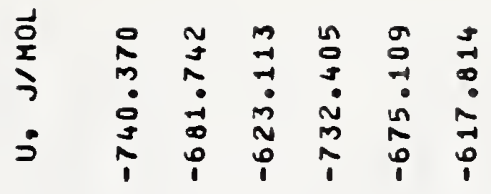

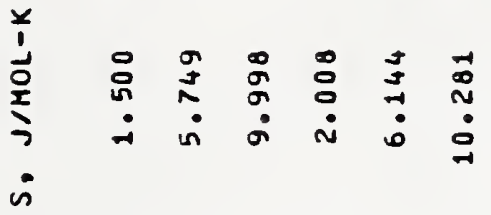

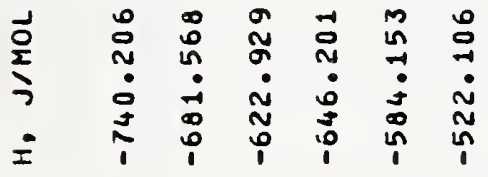

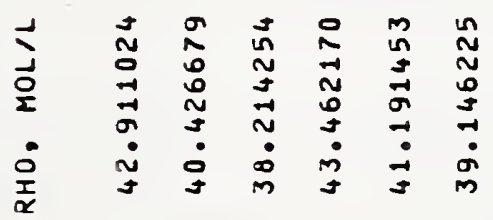

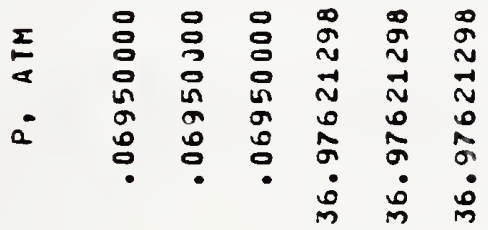

$\stackrel{0}{1}: \dot{0}:$

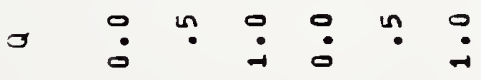

J

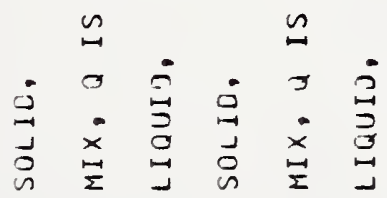

$\begin{array}{lllllll}0 & 0 & 0 & 0 & 0 & 3 & 0 \\ -1 & 0 & 0 & 0 & 0 & 3 & 0 \\ 0 & 0 & i & i & 0 & 0 & 0\end{array}$

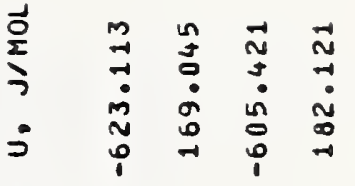

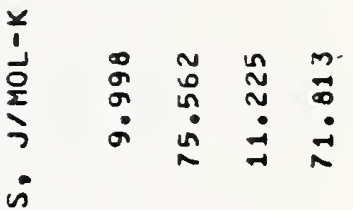

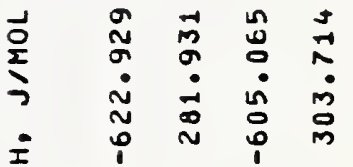

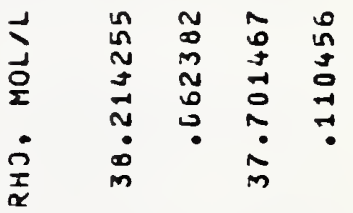

- $\quad \begin{array}{llll}0 & 0 & 0 & 0\end{array}$

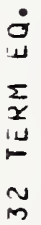

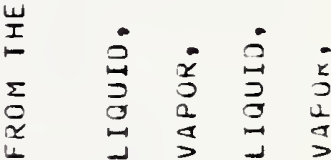

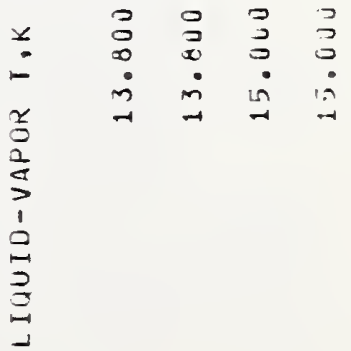




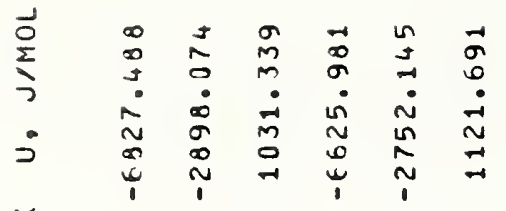

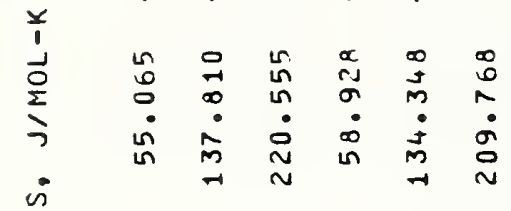

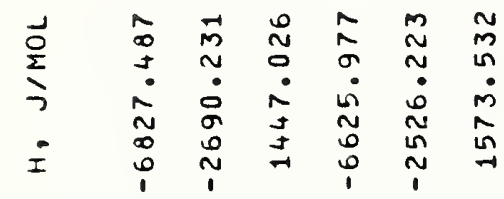

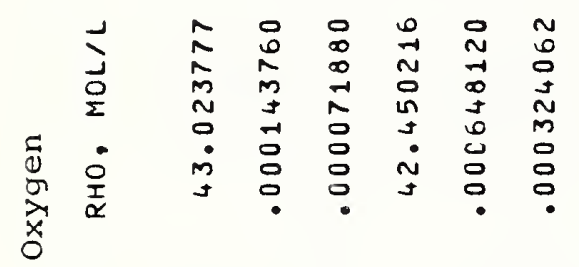

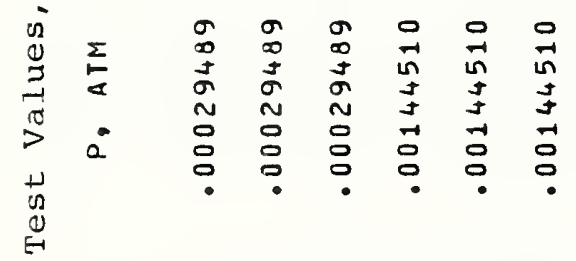

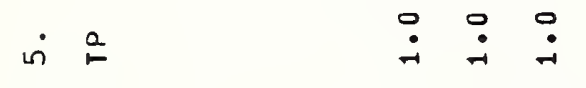

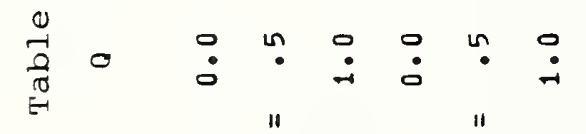

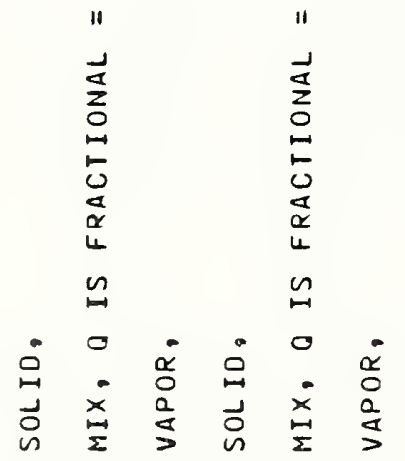

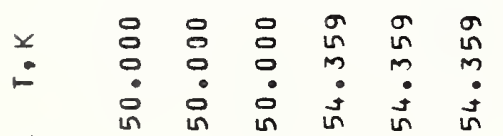

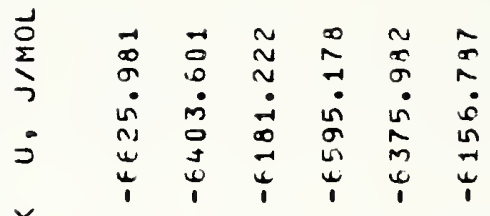

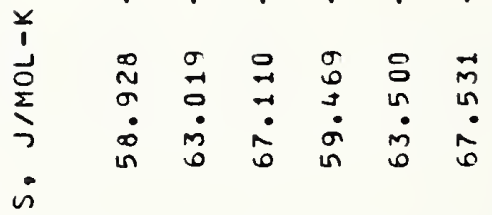

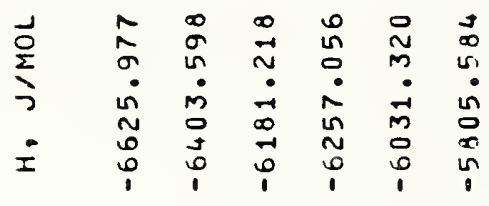

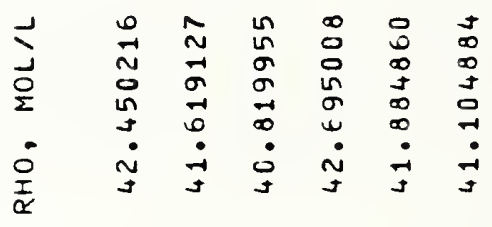

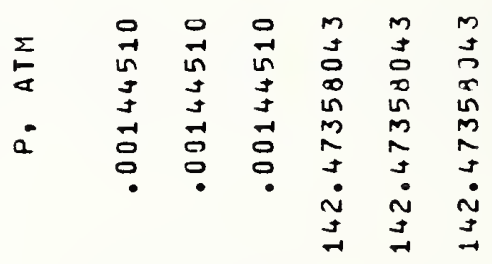

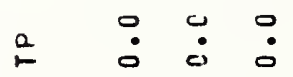

$\begin{array}{lllllll}0 & \dot{0} & \bullet & 0 & \bullet & \bullet\end{array}$

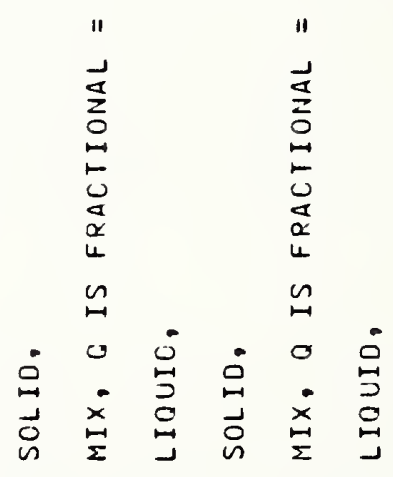

$\because \quad$ in

号

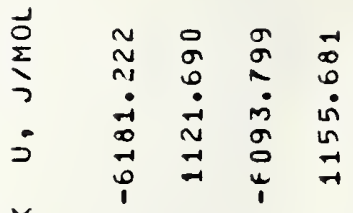

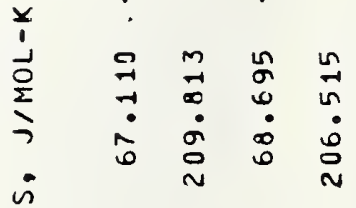

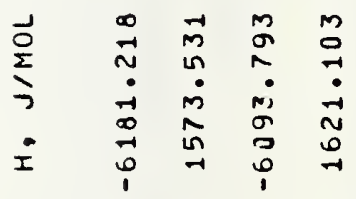

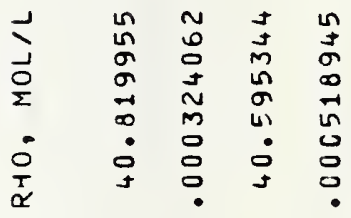

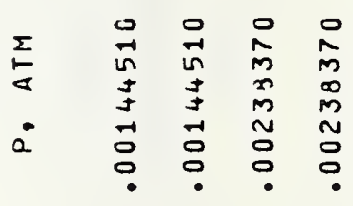

$\stackrel{2}{1}$

$\because \quad: \quad \therefore \quad: \quad \div$

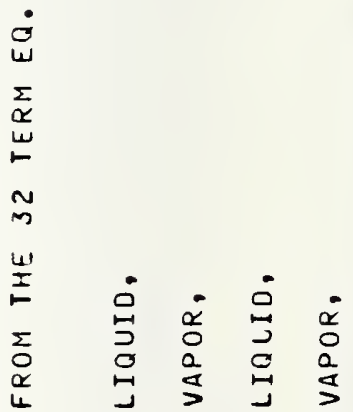

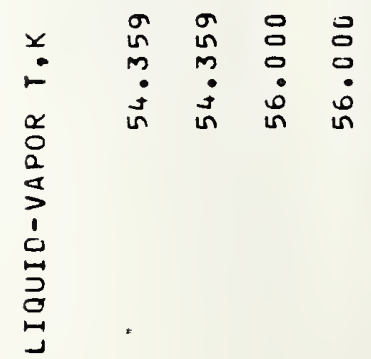


Table 6. Estimates of Maximum Uncertainties

Variable

temperature

pressure

density

enthalpy,

internal

energy

entropy

\section{$1.5 \mathrm{~J} / \mathrm{mol}$ for solid-vapor}

Hydrogen

$0.01 \mathrm{~K}$

lo at the triple point increasing to $200 \%$ at very low temperatures. Negligible for pressures above $1 \mathrm{~atm}$.

$0.2 \%$ at temperatures above T.P. $0.4 \%$ at the triple point increasing to $1.5 \%$ at $4 \mathrm{~K}$.

$1.2 \mathrm{~J} / \mathrm{mol}$ for solid-liquid

$0.08 \mathrm{~J} / \mathrm{mol}-\mathrm{K}$ for solidliquid

$.146 \mathrm{~J} / \mathrm{mol}-\mathrm{K}$ for solid-vapor
Oxygen

$0.01 \mathrm{~K}$

lo at the triple point increasing to $31 \%$ at $44 \mathrm{~K}$. Negligible for pressures above $1 \mathrm{~atm}$.

$0.2 \%$ at temperatures above T.P. $0.6 \%$ for temperatures below the triple point and above the $\beta-\gamma$ transition.

$3 \mathrm{~J} / \mathrm{mol}$ at the triple point increasing to $27 \mathrm{~J} / \mathrm{mol}$ at the highest pressures.

$3 \mathrm{~J} / \mathrm{mol}$ at the triple point increasing to $6 \mathrm{~J} / \mathrm{mol}$ at the lowest temperature.

$0.05 \mathrm{~J} / \mathrm{mol}-\mathrm{K}$ at the triple point increasing to $0.46 \mathrm{~J} / \mathrm{mol}-\mathrm{K}$ at the highest pressures.

$0.05 \mathrm{~J} / \mathrm{mol}-\mathrm{K}$ at the triple point increasing to $0.13 \mathrm{~J} / \mathrm{mol}-\mathrm{K}$ at the lowest temperature.

Entropy errors are approximated by considering enthalpy errors divided by the temperature and vice versa. For hydrogen the entropy departure for the solid-vapor region is taken from the closed loop third law calculation of Roder, et al. (1965). For the solid-liquid region we use the experimental estimate of $1 \%$ in measured heats of fusion published by Dwyer, et al. (1965b). For oxygen we use a value of $3 \mathrm{~J} / \mathrm{mol}$ as error estimate in enthalpy (Weber, 1977b) and add to this either 6\% of the heat of fusion to get the solid-liquid departures, or the enthalpy equivalent of $0.5 \%$ of the values of $\mathrm{C}_{\mathrm{SAT}}$ to get the solid-vapor deviations. The rather large discrepancies described in an earlier version of this report (letter report, June 1977) have indeed been resolved, i.e., reduced considerably, by using a PVT surface which is consistent with the melting line and the triple point.

The work described here has led indirectly to a review of the molar volume of solid oxygen (Roder, 1977). One conclusion of that review is that the volume change on fusion at the triple point is uncertain by about $0.6 \%$. Further experimental work to accurately measure this volume change at essentially zero pressure is recommended. Additional experimental work on oxygen may be required particularly if large scale use of slush oxygen and hydrogen is likely. The sponsor should arrange to have the dielectric 
constant of oxygen reviewed and measured for the solid since this property will be required for quantity gaging. In section 5 we indicate that the thermodynamic properties for the solid-liquid region for oxygen had to be estimated. Some experimental measurements are required to define the properties adequately. We suggest that measurements of the heat of fusion or the volume change on fusion be conducted for oxygen at elevated pressures. An alternative possibility is to measure heat capacity values for oxygen in the solid state. Finally, a review of Prandtl and Grashoff numbers should be made, to include values of $C_{p}, C_{V}$ thermal conductivity and viscosity. Several of these properties are presently not defined for a slush regime, yet they will be needed to define heat transfer characteristics.

\section{SUMMARY}

Computer programs to describe the thermodynamic properties of slush hydrogen and slush oxygen have been developed. The range of temperature for these programs is from several degrees below the triple point to several degrees above the triple point. The upper temperature limit coincides with a pressure limit of about 5000 psia $\left(34 \mathrm{MN} / \mathrm{m}^{2}\right)$. In the case of oxygen the experimental data are very limited and the properties calculated are in the nature of a "best estimate." The equilibrium and thermodynamic properties included are temperature, pressure, density, enthalpy, entropy, internal energy, and quality. Input to the programs is temperature and quality, the remaining variables are outputs. 
1. Ahlers, G., Some properties of solid hydrogen at small molar volumes, Rept. No. UCRL-10757 (Sep 1963), Contr. No. W-7405-ENG-48, (Ph.D. Thesis).

2. Anderson, M. S., Swenson, C. A., Experimental compressions for normal hydrogen and normal deuterium to $25 \mathrm{kbar}$ at $4.2 \mathrm{~K}$, Phys. Rev. Bl0, 5184-91 (Dec 1974).

3. Aoyama, S. I. and Kanda, E., Vapour tensions of oxygen and nitrogen in the solid state, Sci. Repts. Tohoku Univ. First Ser. Vol 23, No. 4, 107-15 (1935).

4. Barrett, C. S., Meyer, L., and Wasserman, J., Expansion coefficients and transformation characteristics of solid oxygen, Phys. Rev. 163, 851-4 (Nov 1967).

5. Bartholome, E., Zuer thermischen und calorischen Zustandsgleichungen der kondensierten Wasserstoffistopen.***On thermal and calorimetric equations of state of condensed hydrogen isotopes, Z. Physik. Chem. B33, 387-404 (1936).

6. Borovik, E. S., Grishin, S. F. and Grishina, E. Ya., The vapor pressure of nitrogen and hydrogen at low pressures, Soviet Phys. Tech. Phys. $\underline{5}$, 506-11 (Nov 1960); English Translation from Zhur. Tekh. Fiz. 30, 539-45 (May 1960).

7. Cook, G. A., Dwyer, R. F., Berwaldt, O. E., et al., Pressure-volumetemperature relations in solid parahydrogen, J. Chem. Phys. 43, 1313-16 (Aug 1965).

8. Dwyer, R. F., Cook, G. A., Berwaldt, O. E. and Nevins, H. E., Molar volume of solid parahydrogen along the melting line, J. Chem. Phys. $\underline{43}$, 801-5 (Aug 1965a).

9. Dwyer, R. F., Cook, G. A., Shields, B. M., et al., Heat of fusion of solid parahydrogen, J. Chem. Phys. 42, 3809-12 (Jun 1965b).

10. Giauque, W. F. and Johnston, H. L., The heat capacity of oxygen from 12 degrees $K$ to its boiling point and its heat of vaporization. The entropy from spectroscopic data, J. Am. Chem. Soc. 51, 2300-21 (Aug 1'929).

11. Goodwin, R. D., Melting pressure equation for the hydrogens, Cryogenics $\underline{2}$, 353-55 (Dec 1962). 
12. Harrison, H., Fite, W. L. and Guthrie, G. L., Chemical reactions using modulated free radical beams. The vapor pressure of solid hydrogen in the temperature range from 4.7 degrees $\mathrm{K}$ to 11.1 degree $\mathrm{K}, \mathrm{Final}$ Rept. No. AFOSR-2357, Contr. No. AF $49(638)-301, \mathrm{GA}-2972$, Proj. No. 38 (Feb 1962 ).

13. Kemp, W. R. G. and Pickup, C. P., The transition temperature of solid oxygen, Temperature, Its Measurement and Control in Science and Industry Vol 4, Pt. 1, Proc. Fifth Symp. on Temperature, Washington, D.C., Jun 21-24, 1971. Instrument Society of America, Pittsburgh, Pa., pp 217-24 (1972).

14. Manzhelii, V. G., Tolkachev, A. M. and Voitovich, E. I., Thermal expansion of crystalline nitrogen, oxygen, and methane, Phys. Status Solidi 13, 351-8 (1966).

15. Mullins, J. C., Ziegler, W. T. and Kirk, B. S., The thermodynamic properties of parahydrogen from 1 degree to 22 degrees $\mathrm{K}$, Georgia Inst. of Technol., Atlanta, Tech. Rept. No. 1, Contr. No. CST-7339, Proj. No. A-593 (Nov 1961).

16. Mullins, J. C., Ziegler, W. T. and Kirk, B. S., The thermodynamic properties of oxygen from 20 degrees to 100 degrees $\mathrm{K}$, Georgia Inst. of Technol., Atlanta, Tech. Rept. No. 2, Contr. No. CST-7339, Proj. No. A-593 (Mar 1962).

17. Roder, H. M., The molar volume (density) of solid oxygen in equilibrium with vapor, submitted to J. of Phys. and Chem. Ref. Data (1977).

18. Roder, H. M., Childs, G. E., MCCarty, R. D. and Angerhofer, P. E'., Survey of the properties of hydrogen isotopes below their critical temperatures, Nat. Bur. Stand. (U.S.), Tech. Note 641 (Oct 1973).

19. Roder, H. M., MCCarty, R. D., A modified Benedict-Webb-Rubin equation of state for parahydrogen-II, Nat. Bur. Stand. (U.S.), Internal Rept. No. 75-814 (Jun 1975).

20. Roder, H. M., Weber, L. A. and Goodwin, R. D., Thermodynamic and related properties of parahydrogen from the triple point to 100 degrees $K$ at pressures to 340 atmospheres, Nat. Bur. Stand. (U.S.), Monograph 94 (Aug 1965).

21. Sindt, C. F., Ludtke, P. F., and Roder, H. M., Slush and boiling methane characterization, National Bureau of Standards, Boulder, Colo., Unoublished report (Jul 1970).

22. Sindt, C. F. and Mann, D. B., Temperature-entropy diagram for parahydrogen triple-point region, Nat. Bur. Stand. (U.S.), Tech. Note 343 (Jun 1966). 
23. Stewart, R. B., Jacobsen, R. T. and Myers, A. F., The thermodynamic properties of oxygen and nitrogen, NASA-CR-128525, Contr. No. NAS9-12078 (Aug 1972).

24. Tolkachev, A. M. and Manzhelii, V. G., Density of solidified gases, Soviet Phys. Solid State 7, 1711-3 (Jan 1966); Transl. Fiz. Tverd. Tela $\underline{7}, 2125-8$ (Jul 1965).

25. Weber, I. A., P-V-T, thermodynamic and related properties of oxygen from the triple point to $300 \mathrm{~K}$ at pressures to $33 \mathrm{Mn} / \mathrm{m}^{2}$, J. Res. Nat. Bur. Stand. (U.S.), A74, 93-129 (Jan-Feb 1970).

26. Weber, I. A., Thermodynamic and related properties of oxygen from the triple point to $300 \mathrm{~K}$ at pressures to 1000 bar, Nat. Bur. Stand. (U.S.), Internal Report 77-865 (Oct 1977); also NASA Ref. Publ. No. RP-1011, pages (Oct 1977). Available National Technical Information Service, Springfield, VA, Order No. NASA RP-1011 (1977a).

27. Weber, I. A., A modified Benedict-Webb-Rubin equation of state for gaseous and liquid oxygen, Nat. Bur. Stand. (U.S.), Internal Report (to be published) (1977b).

28. Woolley, H. W., Scott, R. B. and Brickwedde, F. G., Compilation of thermal properties of hydrogen in its various isotopic and ortho-para modifications, J. Res. Nat. Bur. Stand. (U.S.), 41, 379-475 (Nov 1948). 


\section{APPENDIX A. PROGRAM LISTINGS HYDROGEN}

SUBRUUTINE SLHZ(TT, QQ,TP, PSL, OSL, HSL, SSL, JSL)

THERMOOYMAMIC PROPERTIES FOR SOLIO-VAPOR OR SOLIO-LIQUIO REGIONS TEMPERATURE TT MUST BE BELOW $22.6 \mathrm{~K}$ QUALITY QQ, O. IMPLIES PROPERTIES ON THE JEVSER SIDE 1. IMPLIES PROPERTIES CN THE LESS DENSE SIDE FRACTIONAL QQ SETWEEN J. ANO 1. PERMISSABLE OTHER VALUES JF QQ INVALID

FOR THE SPECIAL CASE OF T=TRIPLE POINT TP=O. MEANS SOLID-LIQUID $T P=1$. MEANS SOLID-VAFOR

DATA (VP1 $=-30.77560949),(V P 2=2.48383094 \bar{U}),(V P 3=4.009857354)$

JATA $(C P 1=-101),.(C P 2=87.75),(C P 3=-26.95833333),(C P 4=4.25)$, 1 (CP5 $=-0.04166060667)$

DATA (V: $=22.77963473),(V 2=-0.031),(V 3=0.005)$

DATA (TTP $=13.800),(T U P=22.63),(H T P=-743.206291),(S T F=1.4999590)$

$T=T T$

$Q=20$

$P S L=O S L=H S L=S S L=U S L=i$

IF (T.LT.TUP) GO TO 1

PRINT 2

2 FORMAT( $\bar{X}, 33 H T$ TOO HIGH, P WILL EXCEED 5000 PSIA) RETURN

1 IF (Q.GE.G. ANO. G.LE.1.J) GO TO

PरINT 4

+ FORMAT(5X,14HQ OUT OF RANGE) RETURN

$5 I F(T-T T P) E, 7,8$

7 IF (TP.E2.J.J) GO TO 8

EITER HERE FOR SOLIU-VAPOR PROPERTIES

- $P S L=E X P\left(V P 1 / T+V P 2^{*} A L O G(T)+V P 3\right) / 760$.

DPOT $=P S L *(-V P 1 / T * 2+V P 2 / T)$

$V S O L=V 1+V 2 * T+V 3 * T * * 2$

OSL $=10 O O . / V S O L$ $H S L=H T P-(C P 1 *(T T P-T)+C P 2 / 2, *(T T P * 2-T * 2)+C>3 / 3 *(T T P * 3-T * 3)$

$1+C P 4 / 4 . *(T T P * * 4-T * * 4)+C P 5 / 5 . *(T T P * 5-T * * 5)) / 1000$. $S S L=S T P-\left(C P 2 *(A L O G(T T F)-A L O G(T))+C P 2^{*}(T T P-T)+C P 3 / 2\right.$ * $(T T P * * 2-T * * 2)$

$1+C P 4 / 3 . *(T T P * 3-T * 3)+C P 5 / 4 . *(T T P * * 4-T * * 4)) / 1000$.

$U S L=H S L-P S L / U S L * 12: .325$

$U S O L=U S L$

IF (Q.EQ.U.し) RETURN

C CONTINUE HERE FOR VAFOR PROPERTIES

DVAP $=F I N O H(F S L, T, 0.06)$

VVAP $=: 03 U$. IOVAP

DEL $V=V V A P-V S O L$

$D E L H=Q E L V * T * D F J T * 0.101325$

OELS $=D E L H / T$

UVAP $=H S L+D E L H-P S L / 11000 . /(0 E L V+10 J 3 . / O S L)) * 101.325$

JELU $=U V A P-U S O L$

IF (Q.NE.1.j) GO TO 9

USL $=100 \mathrm{~J} . /(0 E L V+1000 . / 0 S L)$

$H S L=H S L+U E L H$

USL =HSL-PSL/OSL*:21.325

SSL $=5 S L+D E L S$

RETURN

CONTINUE HERE WITH FRACTIJNAL G

3 JSL $=10 J j . /(Q * J E L V+1032 . / J S L)$

$H S L=Q+D E L H+H S L$

$S S L=Q * J E L S+S S L$ 
$U S L=2 * J E L U+U J L$

RETURN

¿

ENTER HERE FOR SOLIJ-LIQUIJ PROPERTIES

3 PSL $=$ PRESSM (T)

JFOT $=J P C T$ THF $(T)$

DSL $=F I N O M(F S L, T, 43$.

$H S L=E N T H A L(P S L, O S L, T)$

$U S L=H S L=P S L / O S L * 101.325$

$U L I G=U S L$

$S S L=E N T K O P(J S L, T)$

IF IG.EQ. 2 . U R RETUKN

C CONTINUE HERE FOR SOLID PROPERTIES

JELH $=(23.02593154+0.044147 * 0 S L) * 4.184$

DELV $=0 E L H / T / O P O T / 0.024217 \exists / 4.1 \xi+$

DELS $=D E L H / T$

OSL $=1000 . /(1000 . / C S L-E E L V)$

$U S O L=H S L-D E L H-P S L / O S L+1 U 1.325$

JELU $=U L I Q-L S O L$

IF (Q.NE.T.:) GO TO 10

$H S L=H S L-D E L H$

SSL $=S S L-E E L S$

USL $=U S O L$

RETUR:A

- CCNTINUE HERE WITH FRACTIONAL Q

13 JSL $=100 \mathrm{O}, /\left(G^{*} U E L V+10 J 0.10 S L\right)$

$H S L=H S L-Q 7 O E L H$

$S S L=S S L-Q+D E L S$

$U S L=U S L-G * D E L U$

RETURA

Eพ⿰

FUNCTICIV FRESSM (TT)

C CALCULATES MELTING FRESSURE FROA IN INPUT TEMPERATURE

$T=T T+j \cdot j i 3$

21 PS $=.0 E 9 E+(T-13.3 J 3) * 3 j .3312^{*} \equiv X=(-5.693 / T)+(T-13.303)+2.0 * T / 3.0$

I3 $P$ RESZMM

RETURiN

Eis

SUBROUTINE RHOL(:P, DO,TT)

- 1 ST CUT IT RHO FROM $F=A+3 * T$

RE ILLY AI ITERATION, EUT IT MAY EE SMALL ENZUGH ANO FAST ENOUGH

$P$ IV ATM, T IA $K$, RHO IN MOLES/LITER

JIMENSIUN KHO $(43), A(43), 3(-3)$

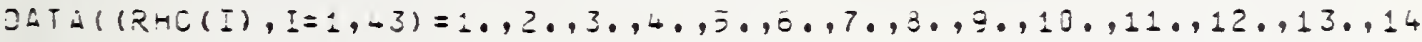

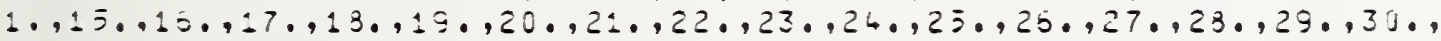

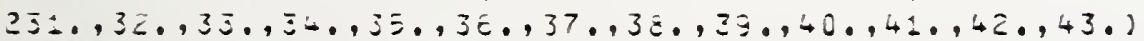

JAiA ( ( $(I), I=:, 43)=-.29593325741,-1.1353455: 75,-2.485: 378102,-4.30$ :

$23.573375655,-23.0316-4295,-28.036458235,-22.772558931,-37.72660571$

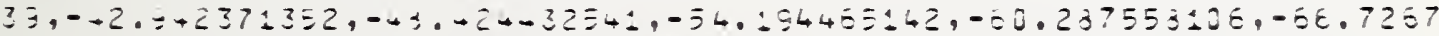

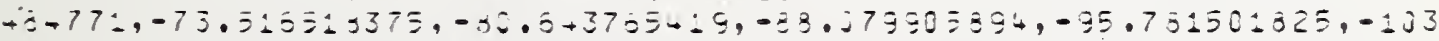

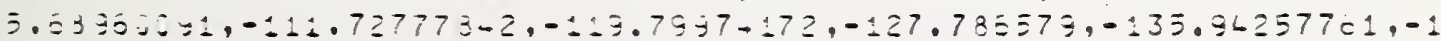

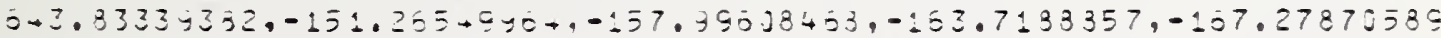

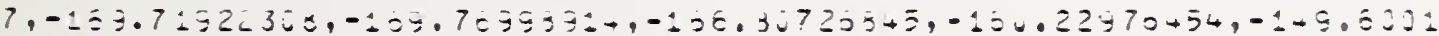

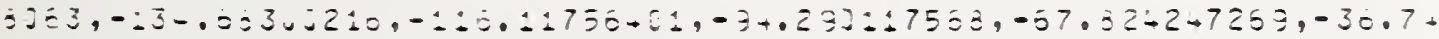

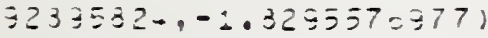

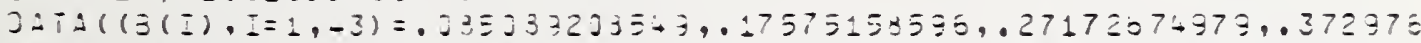

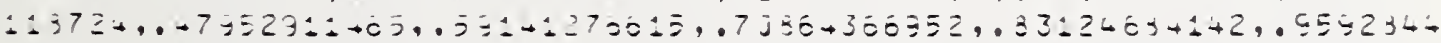

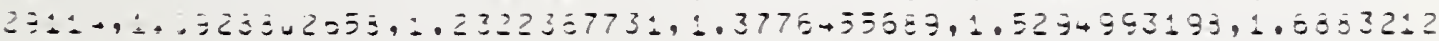

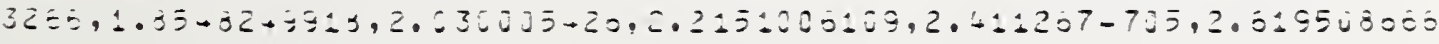


$+5,2.3407043212,3.0750450876,3.325048554,3.5895525008,3.8696893541$, $54.1658593639,4.4782981944,4.8204022069,5.1840092761,5.569646053,5$. $69772524362,0.4057: 75531,6.3214242239,7.2780697825,7.7404616534,8.1$ $7372575502.8 .6358460455,9.3473280676,9.4260953807,9.8132635045,10.2$ $82228136 j, 1 j .03012984,11 \cdot 05913823,11.505307134)$

$10 \quad P=P P$

$T=T T$

I $P=1$

$P L O=0$.

C CHECK INPUT DATA FOR RANGE

INFUT RESTRICTIONS REMOVEO

IF(P.GT.35U.) GO TO 15

IF(T.GT.300.1) GO TO 15

GO TO 13

15 PRINT 16

10 FORMAT (24H INPUT DATA OUT OF RANGE)

$O O=E .0$

RETURN

$P T P=V P N(13.3)$

IF (P.GT.PTF) GO TO:3

IF (T.GT.:3.3) GO TO 18

$D O=0.00001$

RETURN

c

CHECK MELTING LINE

13 IF(T.GT.43.600) GO TO 23

PS $=2 R E S S M(T)$

IF (P-PS) 23,21,19

19 PRINT 22

22 FORMAT (26H INFUT CONDITIONS IN SCLID)

$2: 00=39.5$

RETURN

O PHASEFINDER

23 IF(T.LT.32.938) SO TO 27

FFHASE $=-50.6002+1.920888 * T$

IF (P.GT.FPHASE) IP $=15$

GO TO 36

27 PVAF=VFN(T)

IF $(P-F \vee A P) 36,32,35$

32 PRINT 33

33 FORMAT(53H INFUT FLACES YOU EXACTLY ON THE VAPOR PRESSURE CURVE) JU二JSATL $(T)$

PETURit

3E DEILL OOSATL $(T)$

IF $=0 E N L$

C START TASLE LOOKUP heRE

30 CONTINUE

$3042 I=I P, 43$

$P C A L C=A(I)+3(I) * T$

IF(P.LT.PCALC) GO TO 41

$P L O=P C A L C$

4 CONTINUE

IF (P.LT.PCALC) $I=-3$

IF (P.LT.FCALC) GO TO 4 I

PRINT $\rightarrow 7$

$\rightarrow 7$ FCRMAT(3EH HIGH JENSITY, JUT OF RANGE FOR NOW)

JE $=\rightarrow+$.

RETURN

4 COATINUE

○० $5+j=1, i j$

RHDF $=J$

RHOF = RHOF/:C.

IF (I. ED.1) GO TO 50

$A A=\Delta(I-1)+(A(I)-A(I-1)) * P H O F$ 
$33=3(I-1)+(3(I)-B(I-1)) *$ RHOF

GO TO 52

5J $A A=A(I) * R H C F$

$33=B(I)+R H O F$

52 PCALC $=A A+35 * T$

IF (P.LT.PCALC) GO TO 55

5. PLO $=$ PCALC

$5 \equiv F R A C=(P-P L U) /(P C A L C-F L O) / 10$.

$D D=I-1$

UU $=D O+R H O F-0.1+F R A C$

RETURN

ENTRY TI

C FIRST GUESS FOR TEMPEFATURE ITERATION OF FINOT

$P=P P$

$\mathrm{J}=0 \mathrm{D}$

$0060 \quad I=1,43$

IF(D.LT.RHO(I)) GO TO 61

(S) CONTINUE

$I=43$

61 FPAC $=0-R H O(I-1)$

IF (I.EQ.1) GO TO 53

$A A=A(I-1)+(A(I)-A(I-1)) * F R A C$

$B B=B(I-1)+(3(I)-B(I-1)) * F R A C$

GO TO 02

E 3 FRAC =0

$A A=A(I) * F R A C$

$B j=3(I)+F R A C$

$52 T T=(P-A A) / 33$

ENO

FUNCTION DP JTMP (TT)

- NEW FOP HYJROGEN, MELTING PRESSURE DERIVATIVE

DATA $(T T P=13.833),(A 1=30.3312),(A L=5.693)$

$T=T T+C .003$

$A 2=2.13$.

EXPP $=A 1 * E X F(-A L / T)$

JPOTMF $=(T-T T P) *(E X P P * A L / T * * 2+A Z)+E X F P+A 2 * T$

RETURH

ENJ

FUNCTIUN FIND M(P,T, O)

CHANGED, TRIAL OEVSITY VIA SUBRJUTINE RHO1/T:, 24 FEB 1975

CHANGED TO AUHIT A TPIAL JENSITY FOR SLUSH USE 15 DEC 76

COMMON/CATA/G, R, GAMMA,VF, UTP

UIMENSICN O( 32$), V F(3)$

TYFE JOUSLEG, R, GAIMAA

$T T=T$

IF(D.NE.U.) GO TO 2

CALL RHOL (F,U,TT)

$200=0$

J० $13 \quad I=1,5 j$

CELL FRESSIPF,JO,TT)

$.55=P P$

IF (A3S $(P-P 2)-1, E-7 * F) 20,20,1$

1 CULL JFJJ(TP,00,TT)

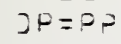

CJPS $=(P \delta-6) / 24$

$j=U C^{-19}$

IF( 23S (COKR) - I.E-7*J) 2J, ZJ, :U

$\therefore \quad 20=J u-c 0 F$

iz Fing $M=J j$

एहiบrit

ENo 
SUBROUTINE SLO2(TT,QQ,TP,PSL, DSL, HSL, SSL,USL)

THERMOOYMAMIC PROPERTIES FOR SOLID-VAPOR OR SOLIO-LIQUIO REGIONS TEMPERATURE TT MUST BE BELOW $58.2 \mathrm{~K}$ QUALITY $Q Q, 0$. IMPLIES PROPERTIES ON THE DENSER SIDE 1. IMPLIES PROPERTIES ON THE LESS DENSE SIDE FRACTIONAL QQ BETWEEN O. AND 1. PERMISSABLE OTHER VALUES OF QQ INVALID

FOR THE SPECIAL CASE OF $T=T R I P L E$ POINT TP=O. MEANS SOLID-LIQUID $T P=1$. MEANS SOLID-VAPOR

DATA $(V P 1=-1096.562485),(V P 2=-2.025578307),(V P 3=28.35976524)$

DATA $(C P 1=16.908081),(C P 2=-0.24181777),(C P 3=0.0024809089)$

OATA $\left(V_{1}=23.2808187\right),\left(V_{2}=-0.06772142868\right),\left(V_{3}=0.001339285715\right)$

DATA $(T T P=54.359),(T U P=58.20),(H T P=-6625.97726),(S T P=58.928478)$

$T=T T$

$Q=Q Q$

$P S L=O S L=H S L=S S L=U S L=0$.

IF (T.LT.TUP) GO TO 1

PRINT 2

2 FORMAT $(5 X, 35 H T$ TOO HIGH, P WILL EXCEED 5000 PSIA) RETURN

1 IF (Q.GE.O. .AND. Q.LE.1.0) GO TO 5

PRINT 4

4 FORMAT $(5 X, 14 H Q$ OUT OF RANGE)

RETURN

5 IF (T-TTP) $6,7,8$

ENTER HERE FOR TRIPLE POINT

7 IF (TP.EQ.0.0) GO TO 8

ENTER HERE FOR SOLID-VAFCR PROPERTIES

$6 P S L=E X P(V P 1 / T+V P 2 * A L O G(T)+V P 3) / 760$.

$D P D T=P S L *(-V P 1 / T * 2+V P 2 / T)$

VSOL $=V 1+V 2 * T+V 3 * T * 2 * 2$

$D S L=1000 . / V S O L$

$H S L=H T P=1 C P 1 * T T P+C P 2 * T T P * 2 / 2,+C P 3 * T T P * 3 / 3,-1 C P 1 * T+C P 2 * T * 2 / 2$.

$1+C P 3 * T * 3 / 3) 1 *$.

$S S L=S T P-\left(C P 1 * A L O G(T T P)+C P 2^{*} T T P+C P 3^{*} T T P * * 2 / 2,-\left(C P 1 * A L O G(T)+C P 2^{*} T+\right.\right.$

$1(P 3 * T * 2 / 2 \cdot 1) * 4.184$

$U S L=H S L-P S L / O S L+101.325$

USOL $=U S L$

IF (O.EQ.0.0) RETURN

C CONTINUE HERE FOR VAPOR PROPERTIES

OVAP $=$ FINCM $(P S L, T, 0.000 E)$

VVAP $=1000.10 V A P$

$D E L V=V V A P-V S O L$

$D E L H=O E L V * T * O P D T * 0.101325$

$D E L S=D E L H / T$

UV $\triangle P=H S L+D E L H-P S L /(100 C . /(O E L V+1000 . / O S L)) * 101.325$

$D E L U=U V A P-U S O L$

IF (Q.NE.1.O) GO TO 9

OSL $=1000 \cdot /(0 E L V+10.30 \cdot 10 S L)$

$H S L=H S L+D E L H$

$U S L=H S L-P S L / O S L * 101.325$

$S S L=S S L+O E L S$

RETURN

CONTINUE HERE WITH FRACTIONAL Q

$9 D S L=10\left(0 . /\left(0^{*} D E L V+1000 . / O S L\right)\right.$

$H S L=Q^{*} D E L H+H S L$

$S S L=C^{*} O E L S+S S L$

$U S L=O * D E L U+U S L$ 


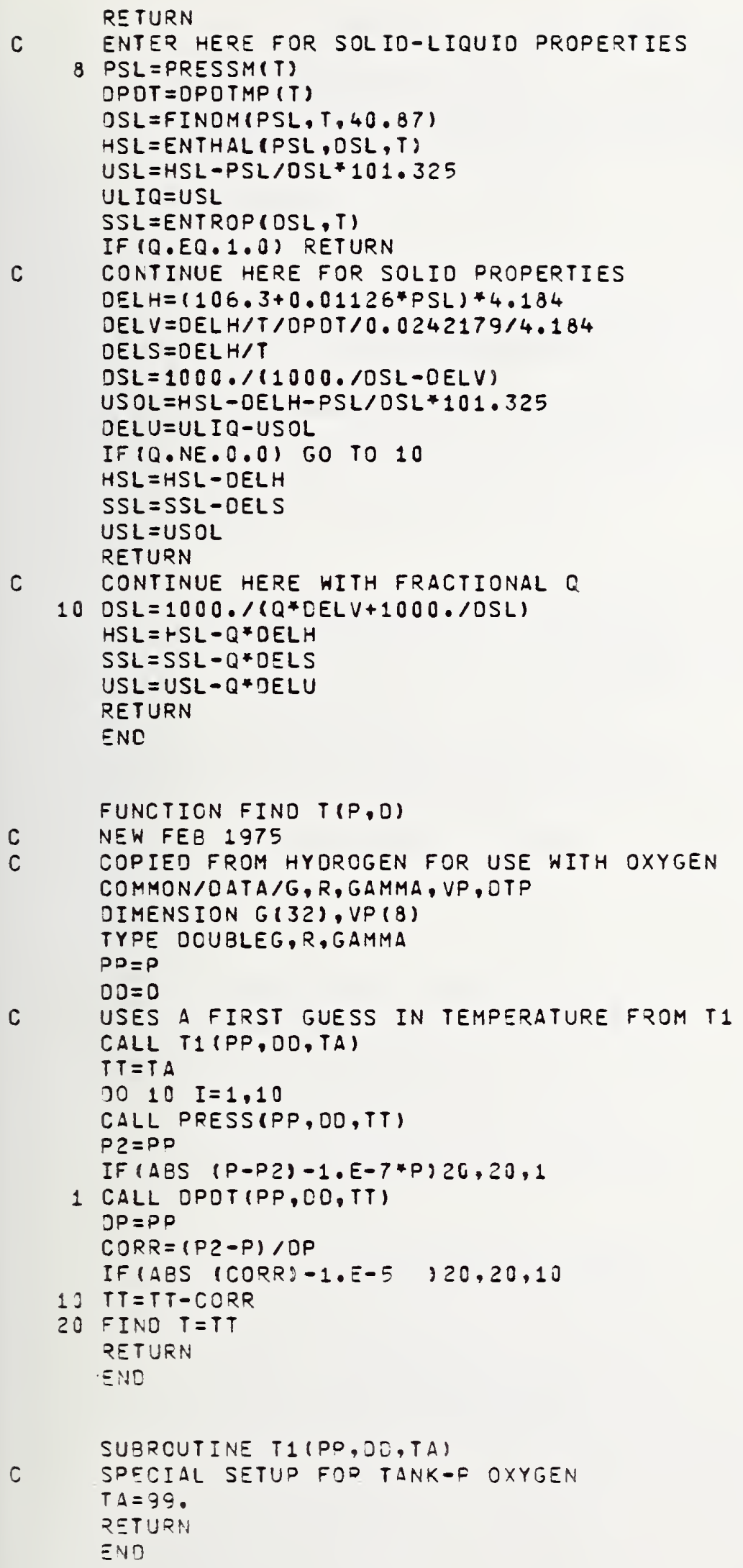


FUNCTION PMELT (PP)

C INVERSE MELTING PRESSURE FOR 02, INPUT $P$, ATM OUTPUT T,K

C NEW HEBER REFERENCES

DATA $(P O=2637.33),(C C=1.769),(T T P=54.359),(P T F=0.0014451)$ $B R A=(P P-P T P, / P 0+1.0$

TEMP $=A L O G(B R A) / C C$

$P M E L T=E X P(T E M P) * T T P$

RETURN

END

FUNCTION PRESSM(TT)

C MELTING PRESSURE FOR 02, INPUT T,K OUTPUT P,ATM

C NEW WEBER REFERENCES

DATA $(P O=2637.33),(C C=1.759),(T T P=54.359),(P T P=0.0014451)$ $P R E S S M=P T P+P O *((T T / T T P) * * C C-1.0)$

RETURN

END

FUNCTION DPDTMP(TT)

C DERIVATIVE OF MELTING CURVE FOR OXYGEN

C NEW WEGER REFERENCES

DATA $(P O=2637.33),(C C=1.759),(T T P=54.359),(P T P=0.0014451)$ DPOTMP $=P O * C C / T T P * * C * T T^{*} *(C C-1.0)$

RETURN

END 
PKOGRAM VALUES (INPUT, OUTPUT)

C THIS FROGRAM TESTS THE SLUSH HYJFJGEN SUBRJJTIVE CALL DATAPHZ

C

COMBIINATIOINS OF SOLID - VAPOR

PRINT 1

$T=12$.

$Q=0$.

CALL SLHZ (T,Q,O, PSL,OSL,HSL,SSL,USL)

PRINT $2, T, Q, \quad$ PSL, OSL,HSL,SSL,USL

$Q=3.5$

CALL SLHZ(T,Q,J,,PSL, CSL, HSL,SSL,USL)

PPINT $3, T, Q, \quad$ PSL,OSL,HSL,SSL,USL

$Q=1$.

CALL SLH2(T,Q,U,,FSL,OSL,HSL,SSL,USL)

PRINT $+, T, Q$, PSL, OSL,HSL,SSL,USL

$T=13.800$

$T F=1$.

$P=\mathrm{j}$.

CALL SLHZ (T,Q,TP, PSL, DSL, HSL, SSL,USL)

PRINT $\bar{J}, T, W, T P, P S L$, USL, HSL, SSL, USL

$Q=j \cdot 5$

CALL SLHZCT, A,TP, PSL, DSL, HSL, SSL, USL:

PRINT $6, T, U, T P, P S L, J S L, H S L, S S L, U S L$

$2=1$.

CALL SLHZ(T,O,TP,PSL, CSL, HSL, SSL,USL)

PRINT $7, T, G, T P, P S L, O S L, H S L, S S L, U S L$

C CUMBINATIONS OF SOLIJ - LIQUID

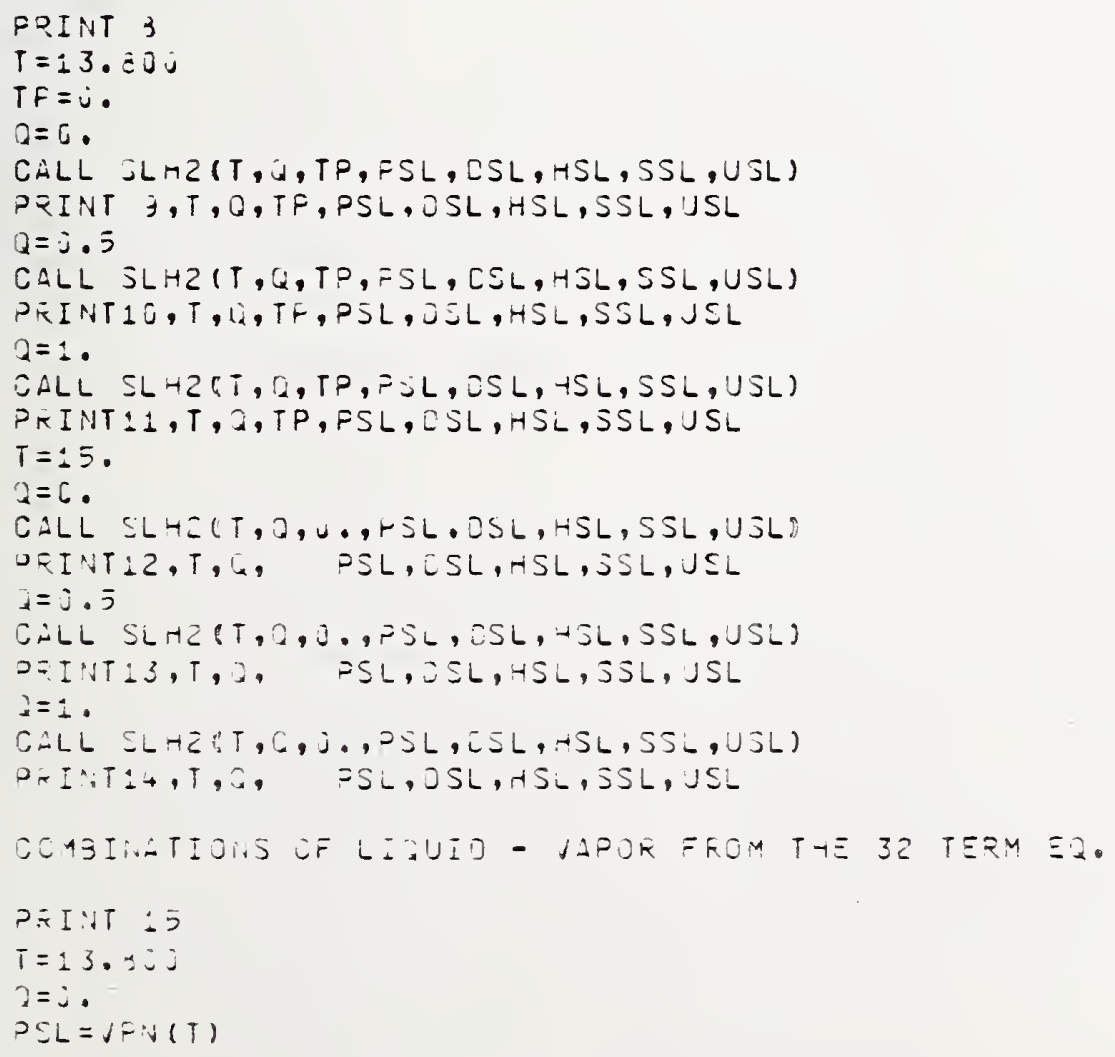


JSL = FINUM (PSL, T, 38. )

HSL = ENTHAL (PSL, JSL, T)

$U S L=H S L-F S L / O S L \# 101.325$

$S S L=E N T R O P(O S L, T)$

PRINT1́, T,Q, PSL, DSL, HSL, SSL, USL

$Q=1$.

JSL=FINCM(PSL, T,O.J6)

HSL =ENTHAL (PSL, OSL, T)

$U S L=H S L-F S L / O S L+1 L 1.325$

SSL $=E N T R O P(D S L, T)$

PRINT17,T,G, FSL,USL,HSL,SSL,USL

$T=15.03 \mathrm{~J}$

$\mathrm{Q}=\mathrm{J}$.

$P S L=V P N(T)$

JSL = FINUM $(F S L, T, 38,1)$

$H S L=E N T H A L$ (PSL, OSL, T)

$U S L=H S L-P S L / D S L * 1[1.325$

$S S L=E N T R O P(O S L, T)$

PRINT16,T,G, FSL,USL,HSL,SSL,USL

$Q=1$.

OSL =FINUM(PSL,T,O.JE)

$H S L=E N T H A L(P S L, O S L, T)$

$U S L=H S L-P S L / U S L+101.325$

$S S L=E N T R O P(J S L, T)$

PEINT 17,T,U, FSL, OSL, HSL,SSL,USL

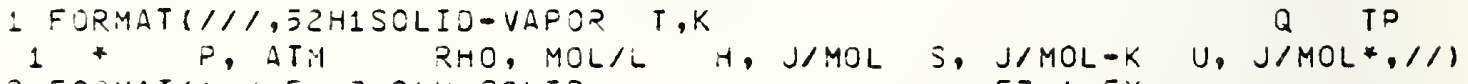

2 FORMATILUX,F3.3,24H SOLIJ,

$1 F 13.0, F: 4.6, F 11.3, F 1 C .3, F 11.3,11$

3 FORMAT $10 X, F 0.3,2+H$ MIX, IS FRACTIONAL $=, F 3.1,5 X$,

$1 F 13.8, F 14.6, F 11.3, F 1 C .3, F 11.3,1)$

$\rightarrow$ FORHAT $(10 X, F 3,3,2+H$ VAPOR,

$1 F 13.3, F 1+0 ., F 1: 3, F:[.3, F 11,3,1)$

¿ FURMATILCX,F3,3,2+H SCLIJ,

: F13.3,F14.6,F11.3,F1C.3,F11.3,/)

J FCPYAT(1OX,F3.3,24H MIX, Q IS FYACTIONAL =,F3.1,F5.1,

i F13.3,F $1+0,0, F 11,3, F 10.3, F 11.3,13$

7 FORIATIIUX,FO.3,24H VAPOR,

$1 F 13 . \delta, F 14.0, F 11.3, F 10.3, F 11.3,11$

3 FORMATI//, JCH SOLIJ-LIQUIJ T,K

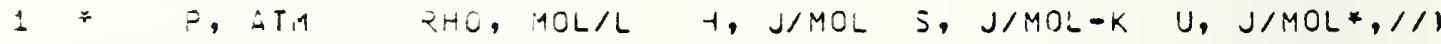

3 FCRMATI1UX,F8.3,24H SOLIJ, ,F3.1,F5.1,

$1 F: 3.8, F 14,0, F 11,3, F 1 \cup .3, F 11.3,1)$

13 FURMATILX,F3.3,2+H MIX, D IS FRACTIONAL =,F3.1,F5.1,

$1 F 13.3, F 14,0, F 11,3, F: 2.3, F 11,3,1)$

¿I FCRMATIICX,F8.3,24H LILUIJ,

$1 F 13.3, F: 4.6, F 11,3, F 10.3, F 11.3,11$

12 FORAATILCX,FY, 3,24H SOLIJ,

$1 F 13 .:, F 14.0, F: 1,3, F \pm 0.3, F 11.3,1\}$

$, F 3 \cdot 1, F 5.1$,

3 FOPMAT(1LX,FJ.3, 26M MIX, 2 IS FRACTIONAL $=, F 3.1,5 x$,

$1 F 13.8, F: \infty .=, F 11.3, F: 0,3, F 11.3,11$

$\therefore$ FORHATIIOX,F3.3,24H LIQUIJ,

IF13.3,F:4,0,F11.3,F12.3,F11.3, I)

IJ FORMATI/1, E2H LIQUID-VAPOR T,K FRCM THE 32 TERM EG. Q TF

1 * $P$, ATM KHC, MOL/L H, J/MOL S, J/MOL-K U, J/MOL*,//I

L= FORMATI10X,F3.3,24H LIGUIJ,

$1 F 13,8, F 14,0, F: 1,3, F 12.3, F: 1.3,11$

17 FOXMATILU,FE.3,2-H VIPOR,

$1 F 13,0, F 1+.0, F 11,3, F 1[.3, F 11,3,11$

$, F 3 \cdot 1, F 5.1$,

, F3.1.5x ,

$\bar{E}+\bar{L}$

, F3.1, $5 x$,

, F3.1,5x, 
PROGRAM VALUES (INPUT, OUTPUT)

C THIS PROGRAM TESTS THE SLUSH OXYGEN SUBROUTINE

CALL DATAOZ

COMBINATIONS OF SOLID - VAPOR

PRINT 1

$T=50$.

$Q=6$.

CALL SLO2 (T,Q, O, PSL, DSL,HSL, SSL, USL)

PRINT $2, T, Q, \quad$ PSL, OSL,HSL, SSL,USL

$Q=0.5$

CALL SLO2 (T,Q, O.,PSL,OSL,HSL,SSL,USL)

PQINT $3, T, Q, \quad$ PSL, DSL,HSL,SSL,USL

$Q=1$.

CALL SLO2(T, Q, O.,PSL,OSL, HSL,SSL, USL)

PRINT $4, T, Q, \quad P S L, D S L, H S L, S S L, U S L$

$T=54.359$

$T P=1$.

$Q=5$.

CALL SLO2(T,Q,TP,PSL, OSL,HSL,SSL,USL)

PRINT $5, T, Q, T P, P S L, D S L, H S L, S S L, U S L$

$Q=0 . \Xi$

CALL SLOZ(T,Q,TP, PSL, OSL, HSL,SSL, USL)

PQINT $6, T, Q, T P, P S L, D S L, H S L, S S L, U S L$

$Q=1$.

CALL SLOZIT,Q,TP,PSL, OSL,HSL, SSL, USL)

PRINT $7, T, Q, T P, P S L, O S L, H S L, S S L, U S L$

PRINT 8

$T=54.359$

$T P=0$,

$Q=C$.

CALL SLO2 (T,Q,TP, PSL, OSL, HSL, SSL, USL)

PRINT $9, T, Q, T P, P S L, O S L, H S L, S S L, U S L$

$Q=0.5$

CALL SLO2(T, Q,TD,PSL, DSL,HSL, SSL,USL)

PRINT $10, T, Q, T P, P S L, D S L, H S L, S S L, U S L$

$Q=1$.

CALL SLO2(T,Q,TP,PSL,OSL,HSL,SSL,USL)

ORINT11, T,Q,TP, PSL, OSL, HSL, SSL, USL

$T=55$.

$0=0$.

CALL SLO2(T,Q,O,,PSL, OSL, HSL,SSL, USL)

DRINT12,T,Q, PSL, OSL,HSL, SSL,USL

$2=0.5$

CALL SLOZ(T,Q,O, PSL, DSL, ASL,SSL, USL)

PRINTIZ,T,Q, DSL, JSL,HSL,SSL,USL

$\theta=1$.

CILL SLOZ(T,G,O,, FSL, DSL, HSL, SSL, USL)

PRINT:L,T,Q, PSL, JSL, HSL, SSL, USL

C COMZINATICNS OF LIOUID - VAPOR FROM THE 32 TEFY EQ.

PPINT 15

$T=54.359$ 
$Q=0$.

PSL = VFNIT

$D S L=F I N D M(P S L, T, 41$,

HSL = ENTHAL (PSL, OSL, T)

$U S L=H S L-P S L / O S L * 101.325$

$S S L=E N T R O P(D S L, T)$

PRINT16,T,Q, PSL, DSL,HSL, SSL, USL

$Q=1$.

OSL $=F I N D M(P S L, T, 0.0003)$

$H S L=E N T H A L$ (PSL, DSL, T)

$U S L=H S L-P S L / O S L * 101.325$

$S S L=E N T R O P(D S L, T)$

PRINT17,T,Q, PSL,DSL,HSL,SSL,USL

$T=56$.

$\mathrm{Q}=\mathrm{C}$.

$P S L=V P N(T)$

OSL = F INOM (PSL, $T, 41,1$

$H S L=E N T H A L$ (PSL, DSL, $T$ )

$U S L=H S L-P S L / O S L+101.325$

$S S L=E N T R O P(D S L, T)$

PRINT16,T,Q, PSL, OSL,HSL,SSL, USL

$Q=1$.

$O S L=F I N O M(P S L, T, 0.0003)$

$H S L=E N T H A L(P S L, D S L, T)$

$U S L=H S L-P S L / O S L * 101.325$

$S S L=E N T R O P(O D S L, T)$

PRINT17,T,Q, PSL, OSL,HSL, SSL, USL

1 FORMATI///,52H1SOLID-VAPOR T,K TP

1 * $P$, ATM RHO, MOL/L H, J/MOL S, J/MOL-K U, J/MOL*,//)

2 FORMATI10X,F8.3,24H SOLID,

$1 \mathrm{~F} 13.8, F 14.6, F 11.3, F 10.3, F 11.3, / 1$

3 FORMAT $(10 X, F 8,3,24 \mathrm{H} M I X, Q$ IS FRACTIONAL $=, F 3.1,5 X$,

$1 \mathrm{~F} 13.8, F 14,9, F 11,3, F 10,3, F 11,3,1)$

4 FORMAT $113 X, F B .3,24 H$ VAPOR,

$1 \mathrm{~F} 13.8, F_{114.9, F 11.3, F 10.3, F 11.3,11}$

5 FORMAT $(10 \times, F 8,3,24 \mathrm{H}$ SOLID,

$1 F 13.8, F 14.6, F 11.3, F 10.3, F 11.3,11$

6 FORMAT $110 X, F 8.3,24 \mathrm{H}$ MIX, Q IS FRACTIONAL $=, F 3.1, F 5.1$,

$1 F 13.8, F 14.9, F 11.3, F 10.3, F 11.3, / 1$

7 FORMAT $(10 \times, F 8,3,24 H$ VAPOR,

$1 F 13,8, F 14.9, F 11.3, F 10.3, F 11.3,11$

9 FORMAT $/ / /, 52 \mathrm{H}$ SOLID-LIQUID T,K

1 * P, ATM RHO, MOL/L H, J/MOL S, J/MOL-K U, J/MOL*,//,

9 FORMAT 1 IOX,F3,3,24H SOLID,

$1 F 13.8, F 14.6, F 11.3, F 10.3, F 11.3,11$

10 FORMAT $(10 X, F 8.3,24 \mathrm{H}$ MIX, Q IS FRACTIONAL $=, F 3.1, F 5.1$,

$1 F 13.8, F 14.6, F 11.3, F 10.3, F 11.3,1)$

11 FOPMAT $(10 \times, F 8.3,24 \mathrm{H}$ LIOUID,

$1 \mathrm{~F} 13.8, F 14.6, F 11.3, F 10.3, F 11.3,11$

12 FORMAT $110 \times, F 3.3,24 H$ SOLID,

$1 \mathrm{~F} 13.8, F 14.6, F_{11} \cdot 3, F 10.3, F 11.3,19$

13 FORMAT $(10 X, F 8.3,24 \mathrm{H}$ MIX, O IS FRACTIONAL $=, F 3.1,5 X$,

$1 F 13,8, F 14,6, F 11,3, F 10,3, F 11,3,18$

14 . FORYAT $110 X, F 3,3,24 H$ LIOUID,

$1 F 13 \cdot 8, F 14,6, F 11,3, F 10.3, F 11,3,1)$

15 FORMAT///,52H LIQUID-VAPOR T,K FROM THE 32 TERM EQ. Q TP

1 * P, ATM RHO, MOL/L H, J/MOL S, J/MOL-K U, J/MOL , //

16 FORMAT $110 X, F 8,3,24 \mathrm{H}$ LIQUIO,

$1 F 13,8, F 14.6, F 11.3, F 10.3, F 11.3,1)$

17 FORMAT $11 \mathrm{JX}, \mathrm{F} 8.3,24 \mathrm{H}$ VAPOR,

$1 F 13.8, F 14.9, F 11,3, F 10.3, F 11.3,11$

END 
APPENDIX E. CONVERSION FACTORS, HYDROGEN

Temperature

Pressure

Specific Volume

Internal Energy, Enthalpy

Entropy, Specific Heat

Thermal conductivity

Viscosity

Speed of Sound

Molecular Weight

Surface Tension
$1.8 \mathrm{R}=1 \mathrm{~K}$

$14.695949 \mathrm{psia}=1 \mathrm{~atm}=1.01325 \times 10^{5} \mathrm{~N} / \mathrm{m}^{2}$

$0.00794590 \mathrm{it}^{3} / \mathrm{Ib} \mathrm{m}=1 \mathrm{~cm}^{3} / \mathrm{mol}$

( $1 \mathrm{~cm}^{3}=0.001$ liter $=10^{-6} \mathrm{~m}^{3}$ )

$0.213405 \mathrm{BTU} / 1 \mathrm{~b}_{\mathrm{m}}=1 \mathrm{~J} / \mathrm{mol}$

$0.118558 \mathrm{BTU} / 1 \mathrm{~b}_{\mathrm{m}} \mathrm{R}=1 \mathrm{~J} / \mathrm{mol}-\mathrm{K}$

$0.0578176 \mathrm{BTU} / \mathrm{ft}-\mathrm{hr}-\mathrm{R}=1 \mathrm{~mW} / \mathrm{cm}-\mathrm{z}$

$0.067196897 \mathrm{Ib} / \mathrm{mt-s}=1 \mathrm{~g} / \mathrm{cm}-\mathrm{s}$

$3.2808 \mathrm{Et} / \mathrm{s}=1 \mathrm{~m} / \mathrm{s}$

2.01594 (on the $\mathrm{c}^{12}=12.000$ scale)

$0.5710147 \times 10^{-5} 1 \mathrm{~b}_{\mathrm{f}} / \mathrm{in}=1 \mathrm{dyn} / \mathrm{cm}$

( I $d y n=10^{-5} \mathrm{~N}$ )

APPENDIX F. CONVERSION FACTORS, OXYGEN

Temperature

Pressure

Specific Volume

Internal Energy, Enthalpy

Entropy, specific Heat

Thermal Conauctivity

Viscosity

Speed of Sound

Molecular weight

Surface Tension
$1.8 R=1 \mathrm{~K}$

14.695949 psia $=1$ atm $=1.01325 \times 10^{5} \mathrm{~N} / \mathrm{m}^{2}$

$0.0005005957 \mathrm{ft}^{3} / 1 \mathrm{~b}_{\mathrm{m}}=1 \mathrm{~cm}^{3} / \mathrm{g} \mathrm{mol}$

$0.0134446 \mathrm{3TU} / 1 \mathrm{~b}_{\mathrm{m}}=1 \mathrm{~J} / \mathrm{g} \mathrm{mol}$

$0.0074692 \mathrm{BTU} / 1 \mathrm{~b}_{\mathrm{m}} \mathrm{R}=1 \mathrm{~J} / \mathrm{g} \mathrm{mol}-\mathrm{K}$

$0.0578176 \mathrm{BTU} / \mathrm{t}-\mathrm{hr}-\mathrm{R}=1 \mathrm{~mW} / \mathrm{cm}-\mathrm{K}$

$0.0671968971 \mathrm{~b}_{\mathrm{m}} /$ Et-s $=I \mathrm{~g} / \mathrm{cm}-\mathrm{s}$

$3.2808 \mathrm{Et} / \mathrm{s}=1 \mathrm{~m} / \mathrm{s}$

31.9988

$0.5710147 \times 10^{-5} 1 b_{\equiv} /$ in $=1 \mathrm{dyn} / \mathrm{cm}$

( 1 dyn $=10^{-5} \mathrm{~N}$ ) 


\begin{tabular}{|c|c|c|c|}
\hline $\begin{array}{l}\text { U.S. DEPT. OF COMM. } \\
\text { BIBLIOGRAPHIC DATA } \\
\text { SHEET }\end{array}$ & $\begin{array}{l}\text { 1. PUBLICATION OR REPORT NO. } \\
\text { NBSIR } 77-859\end{array}$ & $\begin{array}{l}\text { 2. Gov't Accession } \\
\text { No. }\end{array}$ & 3. Recipient's Accession No. \\
\hline \multicolumn{3}{|l|}{ 4. TITLE AND SUBTITLE } & $\begin{array}{l}\text { 5. Publication Date } \\
\text { November } 1977\end{array}$ \\
\hline \multicolumn{3}{|c|}{ THE THERMODYNAMIC PROPERTIES OF SLUSH HYDROGEN AND OXYGEN } & $\begin{array}{l}\text { 6. Performing Organization Code } \\
275.02\end{array}$ \\
\hline \multicolumn{3}{|l|}{$\begin{array}{l}\text { 7. AUTHOR(S) } \\
\text { Hans M. Roder }\end{array}$} & 8. Performing Organ. Report No. \\
\hline \multicolumn{3}{|c|}{ 9. PERFORMING ORGANIZATION NAME AND ADDRESS } & $\begin{array}{l}\text { 10. Project/Task/Wotk Unit No. } \\
2750423\end{array}$ \\
\hline \multicolumn{3}{|c|}{$\begin{array}{l}\text { NATIONAL BUREAU OF STANDARDS } \\
\text { DEPARTMENT OF COMHERCE } \\
\text { WASHINGTON, D.C. } 20234\end{array}$} & $\begin{array}{l}\text { 11. Contract/Grant N॰. } \\
\text { P.O. \# \#6570C }\end{array}$ \\
\hline \multirow{2}{*}{\multicolumn{3}{|c|}{$\begin{array}{l}\text { 12. Sponsoring Organization Name and Complete Address (Street, City, State, ZIP) } \\
\text { NASA-Johnson Space Center } \\
\text { Houston, Texas } 77058\end{array}$}} & $\begin{array}{l}\text { 13. Type of Report \& Period } \\
\text { Covered }\end{array}$ \\
\hline & & & 14. Sponsoring Agency Code \\
\hline
\end{tabular}

16. ABSTRACT (A 200-word or less factual summary of most significant information. If document includes a significant bibliography or hiterature survey, mention it here.)

The thermodynamic properties of hydrogen and oxygen have been calculated for temperatures both below and above the triple point. Values of the various physical properties required for the computations are either taken from the literature, or are extrapolatec. If extrapolated, the extrapolations are based on the known behavior of other simple fluids. The results are presented in the form of computer programs which cover two regions of the phase diagram, solid-vapor, and solid-liquid. Input to the programs is temperature and quality. The properties returned include pressure, density, enthalpy, entropy and internal energy. The present programs for slush hydrogen and slush oxygen are an extension of and depend upon the equations of state developed previously for these gases.

17. KEY WORDS (six to twelve entries; alphabetical order; capitalize only the first letter of the first key word unless a proper name; separated by semicolons)

Computer programs; enthalpy; entropy; hydrogen; internal energy; liquid; oxygen; PVT; quality; slush; solid; vapor.

18. AVAILABILITY EX Unlimited

For Official Distribution. Do Nor Release to NTIS

- Order From Sup. of Doc., U.S. Government Printing Office Washington, D.C. 20402 , SD Car. No. C12

X Order From National Technical Information Service (NTIS) Springfield, Virginia 22151

\begin{tabular}{|l|c|}
\hline $\begin{array}{l}\text { 19. SECURITY CLASS } \\
\text { (THIS REPURT) } \\
\text { UNCL ASSIFIED }\end{array}$ & 21. NO. OF PAGES \\
\hline $\begin{array}{l}\text { 20. SECURITY CLASS } \\
\text { (THIS PAGE) }\end{array}$ & 22. Ptice \\
UNCLASSIFIED & $\$ 4.50$ \\
\hline
\end{tabular}


